\title{
Scientific Challenges to Characterizing the Wind Resource in the Marine Atmospheric Boundary Layer
}

William J. Shaw, ${ }^{1}$ Larry K. Berg, ${ }^{1}$ Mithu Debnath, ${ }^{2}$ Georgios Deskos, ${ }^{2}$ Caroline Draxl, ${ }^{2,3}$ Virendra P. Ghate, ${ }^{4}$ Charlotte B. Hasager, ${ }^{5}$ Rao Kotamarthi, ${ }^{4}$ Jeffrey D. Mirocha, ${ }^{6}$ Paytsar Muradyan, ${ }^{4}$ William 5 Pringle, ${ }^{4}$ David D. Turner, ${ }^{7}$ and James M. Wilczak ${ }^{8}$

${ }^{1}$ Pacific Northwest National Laboratory, Richland, WA 99352

${ }^{2}$ National Wind Technology Center, National Renewable Energy Laboratory, Golden 80401, CO, USA

${ }^{3}$ Renewable and Sustainable Energy Institute, Boulder, CO 80309, USA

${ }^{4}$ Argonne National Laboratory, 9700 South Cass Ave., Lemont IL 60439

$10 \quad{ }^{5}$ Technical University of Denmark, DTU Wind Energy, Risø Campus, Roskilde, Denmark

${ }^{6}$ Lawrence Livermore National Laboratory, Livermore, CA 94550, USA

${ }^{7}$ NOAA/Global Systems Laboratory, Boulder, CO 80305

${ }^{8}$ NOAA/Physical Sciences Laboratory, Boulder, CO 80305

15 Correspondence to: William J. Shaw (will.shaw@pnnl.gov)

\begin{abstract}
With the increasing level of offshore wind energy investment, it is correspondingly important to be able to accurately characterize the wind resource in terms of energy potential as well as operating conditions affecting wind plant performance, maintenance, and lifespan. Accurate resource assessment at a particular site supports investment decisions. Post-construction, accurate wind forecasts are needed to support efficient power markets and integration of wind power with the electrical grid.
\end{abstract}

20 To optimize the design of wind turbines, it is necessary to accurately describe the environmental characteristics, such as precipitation and waves, that erode turbine surfaces and generate structural loads as a complicated response to the combined impact of shear, atmospheric turbulence, and wave stresses. Despite recent considerable progress both in improvements to numerical weather prediction models and in coupling these models to turbulent flows within wind plants, major challenges remain, especially in the offshore environment. Accurately simulating the interactions among winds, waves, wakes, and their structural interactions with offshore wind turbines requires accounting for spatial (and associated time) scales from $\mathrm{O}(1 \mathrm{~m})$ to $\mathrm{O}(100 \mathrm{~km})$. Computing capabilities for the foreseeable future will not be able to resolve all of these scales simultaneously, necessitating continuing improvement in subgrid-scale parameterizations within highly non-linear models. In addition, observations to constrain and validate these models, especially in the rotor-swept area of turbines over the ocean, remains largely absent. Thus, gaining sufficient understanding of the physics of atmospheric flow within and around wind plants remains one of the grand challenges of wind energy, particularly in the offshore environment.

This paper provides a review of prominent scientific challenges to characterizing the offshore wind resource using as examples phenomena that occur in the rapidly developing wind energy areas off the United States. Such phenomena include horizontal temperature gradients that lead to strong vertical stratification; consequent features such as low-level jets and internal boundary layers; highly non-stationary conditions, which occur with both extratropical storms (e.g., nor'easters) and tropical storms; air- 
https://doi.org/10.5194/wes-2021-156

Preprint. Discussion started: 21 February 2022

(C) Author(s) 2022. CC BY 4.0 License.

(c) (1)

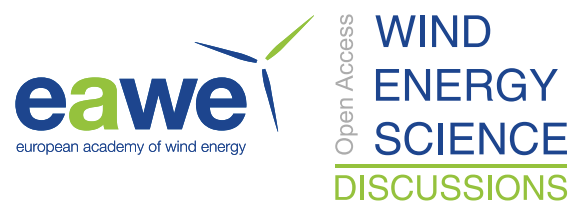

35 sea interaction, including deformation of conventional wind profiles by the wave boundary layer; and precipitation with its contributions to leading-edge erosion of wind turbine blades. The paper also describes the current state of modeling and observations in the marine atmospheric boundary layer and provides specific recommendations for filling key current knowledge gaps.

\section{Introduction}

40 For several decades, utility-scale wind energy has experienced accelerating global growth, with most of the initial focus on land-based production owing to simpler development logistics and lower costs. In the past decade, however, costs for offshore wind energy have also begun to fall dramatically, with a corresponding increase in installation of offshore wind power plants. According to WindEurope (Ramirez et al. 2020), for example, the installed capacity for offshore wind energy production in Europe increased from about $3 \mathrm{GW}$ in 2009 to about $22 \mathrm{GW}$ in 2019. The United States has lagged European development but

45 is now also experiencing accelerating deployment. Forecasts reported in Musial et al. (2019) indicated that the United States may go from $30 \mathrm{MW}$ installed capacity in 2020 to as much as $16 \mathrm{GW}$ by 2030 , and the target has, as of 2021, been raised by the U.S. government to $30 \mathrm{GW}^{1}$. This paper builds on the findings of a workshop organized by the U.S. Department of Energy in 2019 (DOE 2019) that gathered participants from industry, academia, and national laboratories in the United States and Europe to identify the most significant gaps in meteorological and oceanographic knowledge for the development of offshore wind energy.

1 https://www.whitehouse.gov/briefing-room/statements-releases/2021/03/29/fact-sheet-biden-administration-jumpstartsoffshore-wind-energy-projects-to-create-jobs/ (accessed 2 December 2021) 
https://doi.org/10.5194/wes-2021-156

Preprint. Discussion started: 21 February 2022

(c) Author(s) 2022. CC BY 4.0 License.

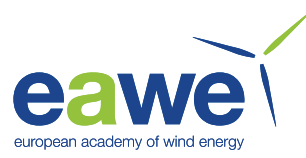

The context for this paper comprises general research needs as well as distinctive features of the U.S. offshore environment that add complexity beyond that which has already been addressed in the European experience (Figure 1). These features include the presence of the Gulf Stream off the East Coast of the United States, westerly winds that commonly advect air off the North American continent toward the east, and the deep-water upwelling and severe coastal topography of the West Coast.

55 Since these features bear similarities to other world regions with deep-water upwelling and western boundary currents, we expect that our articulation of scientific challenges for wind resource characterization will find applicability beyond the United States

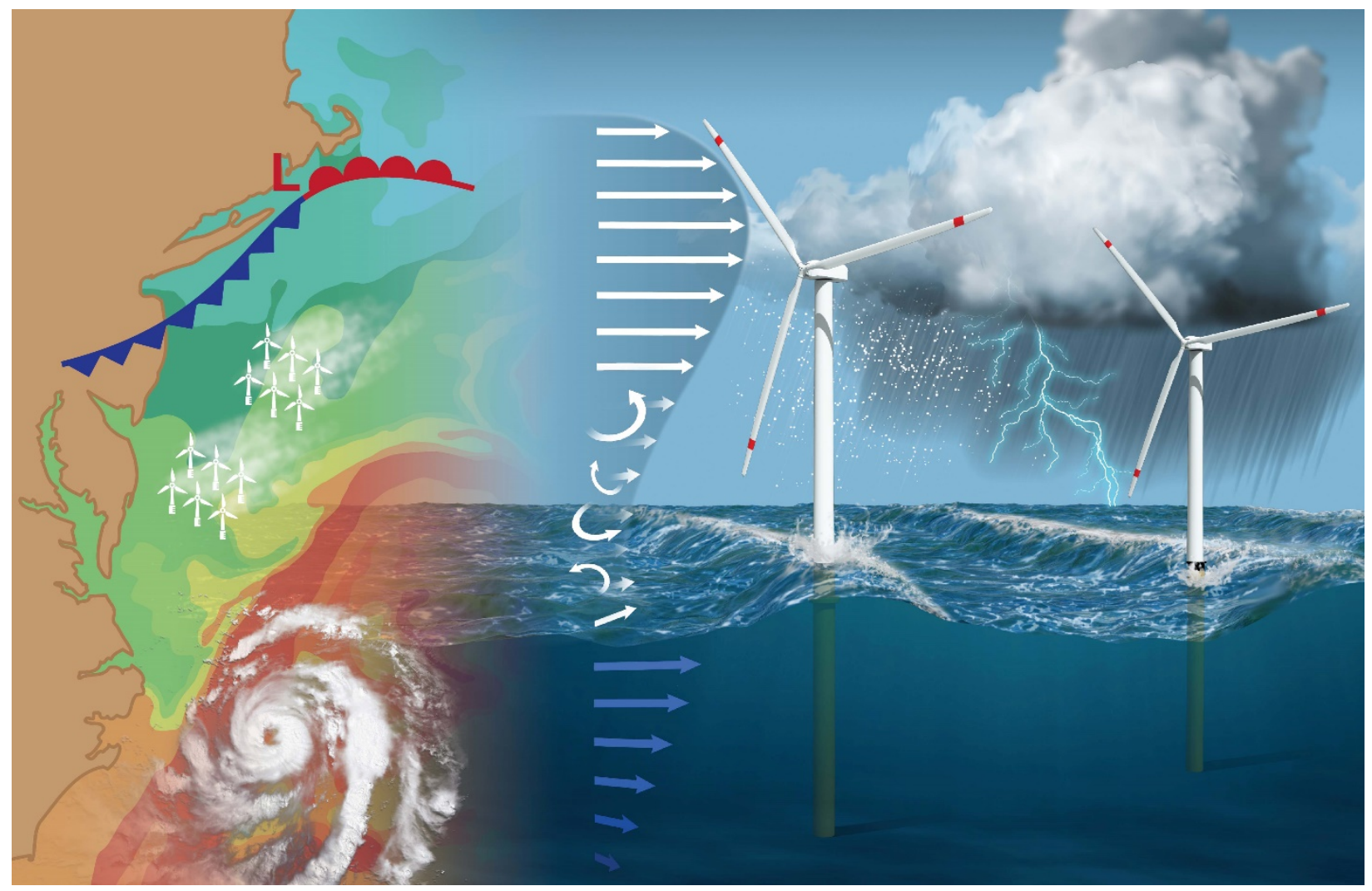

Figure 1: Illustration of phenomena affecting offshore wind plants at varying scales on the U.S. East Coast. Spatial scales range from tropical hurricanes and mid-latitude storm systems such as nor-easters through composite wind plant wakes and low-level jets to breaking waves and small turbulent eddies. The spatial temperature variations arising from the Gulf Stream and the land-sea boundary drive circulations such as sea breezes and modulate thermodynamic stratification. Cloud microphysical processes generate liquid and solid precipitation that can erode leading edges of wind turbine blades.

With the increasing level of offshore wind energy investment, it is necessary to be able to accurately characterize the resource

65 in terms of energy potential as well as operating conditions affecting performance, maintenance, and lifespan. Wind, of course, is the fuel for wind power plants. It is important to accurately assess the resource at a particular site to support investment decisions (e.g., Brower 2012). Once a wind plant is constructed, accurate wind forecasts are needed to support efficient power 
https://doi.org/10.5194/wes-2021-156

Preprint. Discussion started: 21 February 2022

(c) Author(s) 2022. CC BY 4.0 License.

\section{(c) (i)}

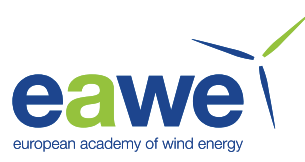

markets and integration of wind power with the electrical grid. Further, optimization of the design of wind turbines requires accurate description of the environmental characteristics, such as precipitation and waves, that erode turbine surfaces (e.g., Dashtkar et al. 2019) and generate structural loads as a complicated response to the combined impact of shear, atmospheric turbulence, and wave stresses (e.g., Vorpahl et al. 2013; Kelley 2011; Kapoor et al. 2020). Recently, considerable progress has been made both in forecast improvement (e.g., Shaw et al. 2019; Wilczak et al. 2019; Olson et al. 2019) and in coupling the real atmosphere to turbulent flows within wind plants (Haupt et al. 2019) over land. Nevertheless, gaining sufficient understanding of the physics of atmospheric flow within and around wind plants remains one of the grand challenges of wind energy, particularly in the offshore environment (Veers et al. 2019).

Modern utility-scale wind turbines typically operate within the atmospheric boundary layer (ABL), the layer of the atmosphere in contact with the surface through which nearly continuous three-dimensional atmospheric turbulence efficiently transports momentum and other scalars (e.g., heat and water vapor; Stull 1988). Characteristics of the ABL that affect wind turbine operation include turbulence motions at many scales and intensities (Kelley 2011; Haupt et al. 2019; Bodini et al. 2020), persistent vertical gradients of mean wind speed (shear) and direction (veer), atmospheric wave activity (e.g., Allaerts and Meyers 2018), and local circulations driven by terrain and by horizontal surface variability such as coastlines (Strobach et al. 2018). Offshore, the ocean forms a dynamic lower boundary to the atmosphere. ABL winds both drive the wave field and are modified by wave roughness of the ocean surface. When winds and waves are not in equilibrium, there can be appreciable deviations from conventional wind profiles (e.g., Patton et al. 2019). Advection of air from western boundary currents, such

85 as the Gulf Stream in North America and the Kuroshio/Oyashio in Asia, can induce strong and persistent thermodynamic stability effects (e.g., Archer et al. 2016) as can upwelling, which occurs off both the Atlantic (e.g., Strobach et al. 2018) and Pacific (e.g., Jacox et al. 2019) coasts of the United States. Stably stratified conditions are associated with significant turbine wake (Lundquist et al., 2018) and upwind blockage effects (Schneemann et al. 2021), with velocity deficits of up to $40 \%$ observed, and wakes remaining detectable for tens of kilometers downstream of the turbines (Christiansen and Hasager 2005; Platis et al. 2018). Finally, the offshore environment of the western North Atlantic, where many U.S.-based offshore wind farms are planned, is susceptible to extreme weather in all seasons of the year. The development of both hurricanes (e.g., Bright et al. 2002) during the warm season and nor'easters (e.g., Businger et al. 2005) during the cool season is supported by the Gulf Stream. Notably, both hurricanes and nor'easters commonly have maximum winds that can interfere with the operation of wind turbines or even cause significant physical damage (Barthelmie et al. 2021). All of these phenomena interact in complex, nonlinear ways over a range of scales that cannot be explicitly resolved in numerical models and that are not fully understood on a theoretical basis.

Accurately simulating the interactions among winds, waves, wakes, and their structural interactions with offshore wind turbines requires accounting for spatial (and associated temporal) scales from $\mathrm{O}(1 \mathrm{~m})$ to $\mathrm{O}(100 \mathrm{~km})$. Because processes on these scales interact non-linearly, it is necessary to account for them simultaneously to fully represent the impact of real atmospheric conditions on turbine structures. Reliable prediction and understanding of turbine power production and structural loading requires high-fidelity numerical simulations of unsteady atmospheric, oceanic, and fluid-structure interaction (FSI) 
dynamics, including atmospheric wake interactions within the plant. Such simulations must be coupled to mesoscale models and data in order to relate wind plant performance to regional weather conditions, including extreme events such as nor'easters and tropical cyclones. Accurately simulating this physical complexity is challenging. Doing so in a single simulation framework is especially challenging because it requires understanding both of process physics and of how to transfer key information across interfaces of coupled models. Moreover, the raw computational power needed to solve these multiscale/multi-physics problems strains current high-performance computing capabilities. Such simulations are at the forefront of current research (e.g., Haupt et al. 2019; Allaerts et al. 2020; Draxl et al. 2020).

An additional, prominent challenge in addressing problems of the offshore environment is a continuing limitation of observations needed to validate the numerical models used to estimate winds and turbulence through the altitudes covered by the rotor plane of the turbines (DOE 2019). Most long-term observations offshore have been made near the surface from buoys, which are sparsely deployed. Even rarer are permanent offshore platforms such as the Air Sea Interaction Tower off the northeastern U.S. coast, which supports both in situ measurements near the surface and remote sensing systems for boundary layer profiling (Kirincich 2020). In Europe, the three offshore FINO towers (Finger 2007) and the one at IJmuiden (Kalverla

115 et al. 2017) can make in situ measurements to approximately 80-100 $\mathrm{m}$ above the surface. No such towers exist in the United States. More recently, buoy-mounted lidar systems (e.g., Gottschall et al. 2014; Viselli et al. 2019; Shaw et al. 2020) have provided multi-seasonal observations of winds and potentially turbulence information to altitudes exceeding $200 \mathrm{~m}$, but there are limited systems that provide publicly available data. Moreover, there are currently no devices available for unattended operation at sea that can provide critical atmospheric thermodynamic profiles. At the same time, wind turbines, especially offshore, are increasing in height and rotor diameter, with the blade tips of the largest current turbines now reaching heights of $250 \mathrm{~m}$ (Gaertner et al. 2020). For a variety of reasons discussed in the sections that follow, surface measurements cannot be used to reliably infer rotor layer wind characteristics.

The following sections provide an overview of the structure of the marine ABL and key challenges in accounting for physical processes within the metocean environment in the context of wind turbine plant design and operation criteria. We address both observational and modeling challenges and provide recommendations for meeting them.

\section{Physical characteristics of the marine ABL}

The physical structure and dynamics of the ABL (e.g., Stull 1988) affect many important flow properties that can strongly modulate wind energy production. A primary characteristic of the marine ABL is its depth, typically marked by a distinct increase in potential temperature $(\theta)$ in a thin layer several hundred meters or more above the surface and here denoted by $\mathrm{z}_{\mathrm{i}}$

130 (Figure 2). This is referred to as an inversion because the temperature commonly increases in this layer. Such inversions can occur for varying reasons throughout the depth of the atmosphere, but the layer at $\mathrm{z}_{\mathrm{i}}$ marks the boundary between the largely turbulence-free atmosphere above and the layer below in which generally continuous turbulence efficiently mixes momentum, heat, water vapor, and other quantities. As in terrestrial environments, marine ABL depth is highly variable, sometimes 
https://doi.org/10.5194/wes-2021-156

Preprint. Discussion started: 21 February 2022

(c) Author(s) 2022. CC BY 4.0 License.

\section{(c) (i)}

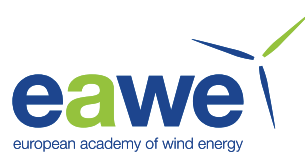

ambiguous, and varies strongly as a function of thermodynamic stability and meteorological forcing. In addition to the potential temperature inversion at $\mathrm{z}_{\mathrm{i}}$, the top of the marine $\mathrm{ABL}$ frequently features a distinct reduction in moisture content (e.g., Zeng et al. 2004).

ABL depth $\mathrm{Z}_{\mathrm{i}}$ is an important parameter used in many scaling relationships and computational approaches to simulating boundary layer flow. It can be estimated from observed profiles of thermodynamic or turbulence variables (e.g., Bianco and Wilczak 2002), but offshore there is a general lack of such observations. Other remote sensing products, such as lidar backscatter intensity (e.g., Luo et al. 2014), lidar-derived variances of water vapor (e.g., Turner et al. 2014), and vertical velocity variances (e.g., Berg et al. 2017), as well as aerosol layers identified using ceilometer data in combination with thermodynamic profiles (e.g., Di Giuseppe et al. 2012) have all been shown to provide credible estimates of $z_{i}$. Each of these approaches has strengths and limitations based on meteorological conditions, including the degree to which aerosol particles, clouds, and fog are present. The greatest limitation at present, however, is the overall lack of these measurement systems in the marine environment. Increased deployment of a variety of remote sensing observation platforms, along with development of improved algorithms to infer marine ABL depth, ideally spanning diverse locations and seasons, would be highly valuable to a broad range of offshore wind energy applications. In addition, spaceborne lidars are beginning to show potential for global mapping of boundary layer depth (Palm et al. 2021).

While the marine ABL shares many characteristics with the terrestrial ABL, important differences apply (Kalvig et al. 2014). Due to the higher thermal inertia of water relative to other surface types, the marine ABL is less sensitive to diurnal forcing than the terrestrial ABL, with generally shallower depths and weaker turbulent mixing during sunlit hours, and weaker static stability overnight (Emeis 2018). However, the slow response of sea surface temperature (SST) to the influence of the temperature of the air above can also lead to very strong convection in the case of cold air flowing over warmer water (e.g., Archer et al. 2016), or strongly stable stratification, when warmer air moves over colder water. Non-zero velocities of ocean currents modulate friction between the atmosphere and the ocean, and horizontal SST gradients resulting from these currents and associated eddies occur over a broad range of spatial scales. This has been identified as an important component of oceanatmosphere coupling (Small et al. 2008; Edson et al. 2013), and the impact of this variability can affect not only marine ABL structure and evolution but also the free troposphere above (e.g., Lambaerts et al. 2013; Wenegrat and Arthur 2018). Despite several previous observational (e.g., Friehe et al. 1991; Chelton 2001; Edson et al. 2007; Spall 2007; O’Neil 2012) and modeling (e.g., Piazza et al. 2016; Skyllingstad et al. 2007; Seroka et al. 2018) studies, the lack of observations beyond localized case studies has left considerable uncertainty in our understanding of modulation of the marine ABL by variations in SST.

Another distinguishing feature of the marine $\mathrm{ABL}$ is that it is frequently capped by a layer of stratocumulus clouds, especially in favored locations such as the U.S. West Coast (e.g., Wood 2012). Turbulence driven by cloud-top radiative cooling,

165 governed predominantly by cloud liquid water content, can be a significant source and modulator of turbulence within the marine ABL (Wood 2012). Moreover, enhanced entrainment from cloud-top cooling can strengthen the inversion at $\mathrm{z}_{\mathrm{i}}$, and 
shear across the inversion can lead to the generation of atmospheric waves. Even in the absence of terrain or other obstructions, these can also strongly modulate flow and turbulence characteristics in the boundary layer (Allaerts and Meyers 2018).

To facilitate understanding of the various processes occurring within its complicated vertical structure, the marine ABL can

be conceptually divided into three layers beneath $\mathrm{z}_{\mathrm{i}}$, as pictured in Figure 2 . The first layer is the wave boundary layer, the layer of the marine ABL in which winds are directly modulated by ocean waves. Immediately above is the surface layer, generally defined as the lowest $10 \%$ of the $\mathrm{ABL}$, within which the wind speed profile is approximately logarithmic, turbulence fluxes are approximately constant with height, and turbulence structure can be scaled with distance from the surface. The remainder of the marine $\mathrm{ABL}$, up to $\mathrm{z}_{\mathrm{i}}$, is characterized by turbulence structure that scales more with the value of $\mathrm{z}_{\mathrm{i}}$ than with distance from the surface. The remainder of this section will describe each of these layers in greater detail.
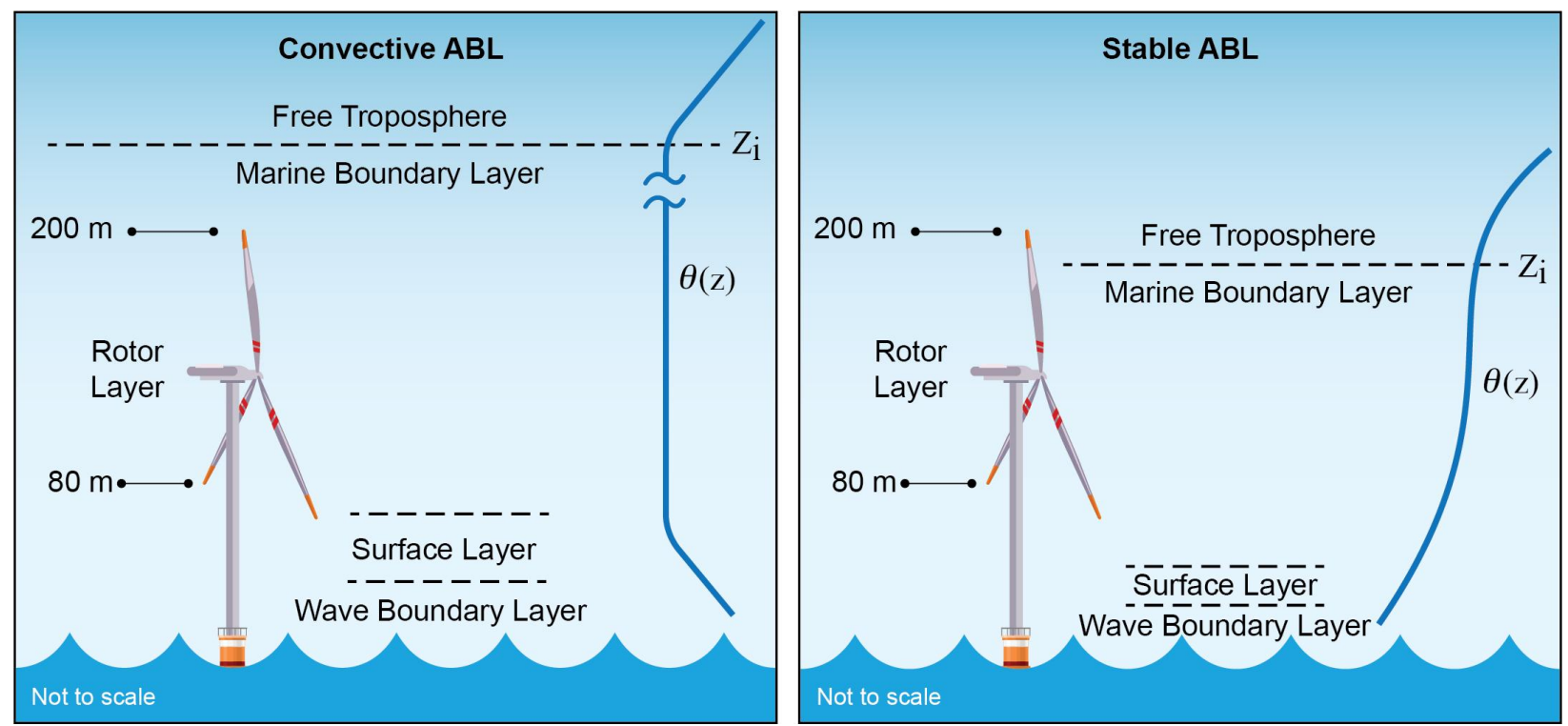

Figure 2: Depiction of the different components of the marine ABL and how those components and overall structure vary with changes of atmospheric stability. $\vartheta$ in the figure is potential temperature and $\mathrm{z}_{\mathrm{i}}$ is the inversion at the top of the boundary layer. The break in the 9 profile indicates that the depth of the convective boundary layer can be much greater than the height of the surface layer. The figure is exaggerated in the vertical for illustration.

\subsection{Wave boundary layer}

In the lowest part of the marine $\mathrm{ABL}$, wave-induced surface motion disturbs the marine surface layer, creating an internal layer known as the wave boundary layer (Figure 2). This layer is in direct contact with the ocean surface, which modulates winds within it through direct dynamic forcing, form drag, dissipation of energy through wave breaking, and other processes

185 (Chalikov 1995; Edson et al. 1999; Sjöblom and Smedman 2003). Many of these processes are not accounted for within the assumptions of Monin-Obukhov similarity theory (M-O theory; Obukhov 1946; Monin and Obukhov 1954) as it is commonly applied to the surface layer (Hare et al. 1997; discussed further below). For example, under the influence of swell propagating faster than the mean wind, wind speed profiles frequently exhibit maxima near the surface in violation of the logarithmic 
https://doi.org/10.5194/wes-2021-156

Preprint. Discussion started: 21 February 2022

(c) Author(s) 2022. CC BY 4.0 License.

\section{(c) (i)}

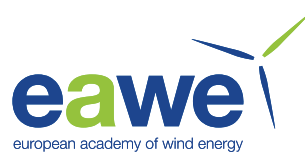

expectation of M-O theory (e.g., Miller et al. 1999; Smedman et al. 2009). Although the depth of the wave boundary layer is commonly considered to be on the order of 1-3 m, impacts of waves may extend to much greater heights, depending on flow conditions (Janssen 2004; Kalvig et al. 2014; Cifuentes-Lorenzen et al. 2018). This extended range of impact has been demonstrated by numerous wave-resolving large-eddy simulation (LES) studies that examined the impacts of waves on wind energy relevant quantities of interest extending well into the rotor layer (described more fully in Section 4; e.g., Husain et al. 2019; Patton et al. 2019; Sullivan et al. 2008, 2014, 2018a, b; Yang et al. 2014). Cifuentes-Lorenzen et al. (2018) noted that the height above the surface to which impacts of air-sea coupling in the wave boundary layer extend remains an active area of research.

\subsection{Surface layer}

The surface layer, generally taken to extend from the wave boundary layer top up to $0.1 \mathrm{zi}$, spans the depth over which energy fluxes may be treated as constant in height and, thus, for which M-O theory may be considered valid (e.g., Garratt 1994; Stull 1988; Arya 2001). Fluxes in well-mixed boundary layers have been observed to vary approximately linearly with height from their surface values to near-zero at the temperature inversion at the top of the marine ABL. This provides the practical basis for treating the surface layer as $10 \%$ of the depth of the well-mixed layer because statistical errors in flux observations are comparable to or larger than 10\% (Schaller 1977; Edson and Fairall 1998; Sjöblom and Smedman 2003). Thus, if the marine $\mathrm{ABL}$ is $1 \mathrm{~km}$ deep, the lowest $100 \mathrm{~m}$ can be treated as the surface layer where M-O theory is applicable and consequent quasilogarithmic wind speed profiles would apply. The height of the marine ABL is often quite shallow over upwelling regions of eastern Oceans (e.g., Wood and Bretherton 2004), perhaps only a few hundred meters deep. Under these conditions, state-ofthe-art wind turbine hub heights may be well above the surface layer, where M-O theory is no longer valid.

M-O theory holds that under conditions for which turbulence is stationary and horizontally homogenous, variables of interest, such as wind shear, can be scaled with surface turbulence fluxes of momentum and buoyancy and with height above the surface. An assumption of this scaling is that the fluxes are invariant with height in the surface layer. While this theory is routinely used to represent marine ABL characteristics (e.g., Kalvig et al. 2014), and to specify surface boundary conditions in its simulations (e.g., Skamarock et al. 2008), conditions under which M-O theory is considered valid are routinely violated in the surface layer of the marine ABL. Non-logarithmic wind speed profiles as well as significant changes in the momentum flux with height have been documented in both observational (Smedman et al. 2009; Archer et al. 2016) and modeling studies

215 (Sullivan et al. 2008). Other assumptions of M-O theory, including steady flow conditions and horizontal homogeneity, are likewise not satisfied over coastal zones or over ocean surfaces when significant swell or wave activity is present or active mesoscale or synoptic scale weather are affecting an area. For example, the roughness of the sea surface varies dramatically in time, often because of distant storms or local conditions (Hanley et al. 2010; Semedo et al. 2011). Weather fronts and tropical disturbances create strong time variations in the local sea state as well as wind and turbulence fields. The strong diurnal cycle over coastal land drives local circulations such as low-level jets (e.g., Pichugina et al. 2012, 2017; DOC/NOAA 2014; Djalalova et al., 2016) and the sea breeze (Seroka et al. 2018). Simulations show that the sea breeze circulation can extend tens 
of kilometers offshore (e.g., Igel et al. 2017), which would affect many potential wind plant locations. Nevertheless, M-O theory remains a widely used conceptual framework for understanding and simulating the surface layer, even over the ocean (Gualtieri 2019).

225 Considerable research has been devoted to developing and validating mixing layer theories as alternatives to M-O theory that would improve the representation of the modeled wind field. For example, Gryning et al. (2007) proposed a theory for the entire ABL, with emphasis on the lowest 200-300 m, that formulates a simple model for the combined length scale controlling the wind profile and its stability dependence by inverse summation of three component length scales. Gryning et al. (2007) and subsequent studies (Peña et al. 2008, 2010) demonstrated the ability of this model to provide more accurate wind speed profiles within the ABL and under all stability conditions compared to that of the standard M-O theory approach; however, the method is only valid over homogeneous terrain. Sathe et al. (2011) extended its validation to offshore conditions; however, meteorological observations used for this validation reached only to a height of $116 \mathrm{~m}$, which is too limited compared to the size of the state-of-the-art offshore wind turbines (blades may extend up to a height of $270 \mathrm{~m}$ as shown in Fig. 2; Gaertner et al. 2020). Holtslag et al. (2017) used meteorological mast observations up to $315 \mathrm{~m}$ above the surface $85 \mathrm{~km}$ offshore in the Dutch North Sea to validate the extended diabatic surface layer wind shear model based on Gryning et al.'s (2007) work. The extended wind shear profiles are found to outperform the traditional surface layer shear profiles for neutral and strongly stable conditions. However, improvements are needed for strongly unstable conditions. Further, the current formulation underestimates wind speeds above $60 \mathrm{~m}$, which is a critical height for wind energy applications. Additional long-term data sets remain a key need for validating and improving models of surface layer winds and turbulence offshore, especially in areas subject to extremes of stability such as regions of strong upwelling or western boundary currents.

\subsection{Mixed layer}

For the remainder of the marine ABL between the surface layer and $\mathrm{z}_{\mathrm{i}}$, the vertical transport of momentum, turbulence kinetic energy (TKE), and other constituents tends to be dominated by large turbulent eddies that scale with $\mathrm{z}_{\mathrm{i}}$ rather than height above the surface as is the case in the surface layer. Atmospheric stability directly affects the depth of the ABL (and therefore the surface layer). Stable conditions are generally associated with much shallower ABL depths than neutral or convective conditions (illustrated in Figure 2). Wind speed profiles during stable stratification also frequently exhibit significantly greater vertical changes of wind speed and direction, often including low-level jets (see further details on stable conditions in Section 3). Such stably stratified vertical distributions of temperature, coupled with strongly sheared winds, can also support a spectrum of atmospheric wave modes that influence wind plant and turbine performance, including breaking Kelvin-Helmholtz and other gravity waves. Breaking gravity waves can sometimes lead to intermittent turbulence bursting events as well as strong wave-turbulence loading on turbines (Kelley et al. 2006). Simulations suggest that gravity waves generated by wind plants in a stable boundary layer on the other can strongly modulate kinetic energy distributions within the plant, thereby influencing the power that can be generated (Allaerts and Meyers 2017, 2018; Wu and Porté-Agel 2017). These studies await validation with observations. 
https://doi.org/10.5194/wes-2021-156

Preprint. Discussion started: 21 February 2022

(c) Author(s) 2022. CC BY 4.0 License.

Upstream obstructions can influence downstream flow in the marine ABL, particularly in the presence of strong static stability. These disturbances to the flow, caused by coastal terrain and cities - and even the wind plants themselves, generate internal boundary layers (IBLs; Garratt 1990; Savelyev and Taylor 2005; Gadde and Stevens 2021). IBLs form in the presence of discontinuities in surface characteristics, including roughness and temperature. These layers gradually deepen with increasing downwind distance within the existing ABL before eventually merging with it through entrainment. Over the distances within which IBL characteristics remain distinct from those of the background boundary layer, impacts on vertical profiles of wind speed, direction, temperature, and turbulence characteristics can be considerable, and can affect the performance of affected wind plants (e.g., Chamorro and Porté-Agel 2011). For IBLs generated by wind plants themselves, wake effects (Frandsen et al. 2007; Nygaard 2014; Pryor et al. 2020) become concerns when new plants influence the resources available to previously constructed plants. Evidence of an offshore wind farm influencing the mixed layer can be seen from photos and has been additionally confirmed in numerical modeling (Hasager et al. 2017; Siedersleben et al. 2018, 2020). Current abilities to simulate IBL characteristics and impacts on operating wind plants need to be further investigated to assess the adequacy of resource characterization and wind plant operation guidelines in areas influenced by IBLs (Borvarán et al. 2021). Observations are needed to characterize how often IBLs form, the significance of their effect on wind and turbulence in the rotor plane, and what model improvements are needed to confidently account for their impact on wind power production.

270 We previously discussed the impact of the ocean surface on the wave boundary layer and the surface layer. Under some conditions, the impact of the wind-wave conditions may affect the wind profile throughout the mixed layer. Studies to date (e.g., Rutgersson et al. 2001; Semedo et al. 2009; Smedman et al. 2009; Sullivan et al. 2008, 2014, 2018a,b; Husain et al. 2019) have been rather idealized, however, and supporting observations remain sparse. As an example, Figure 3 shows the impact of wave-wind alignment on vertical profiles of wind components from an atmospheric LES model with resolved propagating 275 surface waves characterized by a significant wave height of $6.4 \mathrm{~m}$ (Patton et al. 2019). Here, the horizontal and time averaged zonal $<\mathrm{u}>$ and meridional $<\mathrm{v}>$ velocity components, as well as scalar wind speed, all normalized by the friction velocity at 10 $\mathrm{m}$ above the wave surface, are plotted against height zeta scaled by $z_{i}$. The various colors show different orientations of the wave propagation direction (alpha) with respect to the geostrophic wind (10 $\mathrm{m} \mathrm{s}^{-1}$ in the zonal direction). Significant impacts on mean winds emerge throughout the depth of the marine ABL due to differences of the viscous stress and pressure drag 280 effects arising from the different wave orientations.

While a suggestive body of literature is emerging from a growing number of such atmospheric large-eddy simulations studies examining the impact of additional surface wave and atmosphere flow characteristics on ABL mean and turbulence quantities, these numerical investigations have not been sufficiently validated against measurements to yet be regarded as definitive. There is currently little observational information regarding the impact of these conditions on wind shear and turbulence at turbine rotor heights and, consequently, on mechanical loading and power production. 

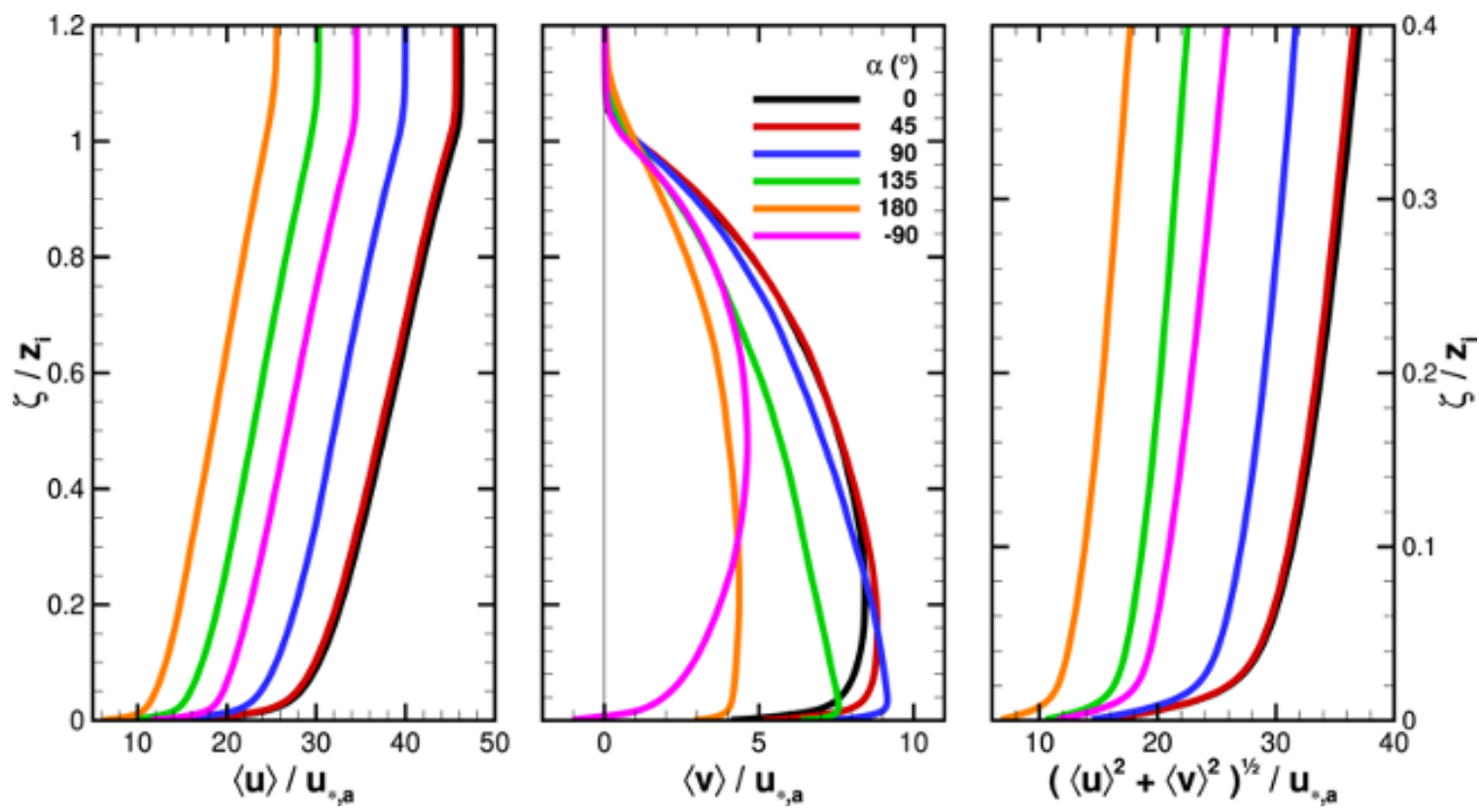

Figure 3: Impacts of various wave propagation directions relative to the mean wind direction on wind components throughout the ABL depth, from wave-resolving atmospheric LES (Patton et al. 2019). Note that $0^{\circ}$ denotes that the wind direction is aligned with the wave propagation direction. The difference in the wind profiles for the $90^{\circ}$ and $-90^{\circ}$ is due to Coriolis force.

\section{The role of stratification and surface temperature heterogeneity}

Boundary layer stratification is a key characteristic of the atmosphere for wind energy because of the impacts that it has on wind speed, wind shear and veer, and turbulence. Stable stratification results in decreased frictional coupling with the surface, with stronger wind speeds for the same forcing than would occur with neutral or unstable stratification. Stable stratification generally is also accompanied by weaker turbulence than neutral stratification, and these weaker turbulence levels allow for turbine and wind plant wakes to propagate greater distances downwind, potentially having a detrimental impact on the wind resource available for other turbines and wind plants as noted in the previous section. The decoupling from the surface and the weaker turbulence allow for larger wind shear and veer to develop, and strongly stable stratification can support atmospheric wave activity, as noted in Section 2. In contrast, unstable stratification is associated with weaker shear and higher turbulence levels. Large shears, intense turbulence, and atmospheric waves can all place increased stress on turbine blades and gears, and it is important to quantify the range of magnitudes that they can reach. Thus, measuring, understanding, and predicting offshore atmospheric stratification is essential for determining both the wind resource and turbine loads.

For regions of the world where the predominant flow brings continental air over offshore wind energy development areas, such as East Asia and eastern North America, the role of atmospheric stability and its impact on offshore atmospheric flow conditions will likely be significantly different from much of the European offshore wind experience. For example, prevailing westerly flow over the North American continent often results in air temperatures that are significantly colder or warmer 
(depending on the season) than the ocean temperature in the Mid-Atlantic and New England coastal regions, leading to both strongly stable and unstable boundary layer stratification. In contrast, for most European offshore wind energy production, prevailing westerly flow across the Atlantic results in offshore European atmospheric temperatures that usually are closer to being in equilibrium with sea surface temperatures, and a greater preponderance of near- neutral stratification (Sathe et al., 2011; Dörenkämper et al., 2015).

The impact of temperature advection on U.S. offshore boundary layer stratification was investigated by Angevine et al. (2006), who found that stable boundary layers were ubiquitous during the summer months in the Gulf of Maine, as warmer continental air advected offshore over the cooler ocean. Mahrt et al. (2001) showed that for flow of warm air from land over cooler water, and for fetches of less than $5 \mathrm{~km}$ from the coast, the turbulence rapidly weakened due to buoyancy destruction and reduced

315 shear generation over the less rough sea surface, indicating that the stabilization and modification of the boundary layer can be rapid. The presence of warm Gulf Stream waters further offshore, and the sharp SST fronts often associated with it, can also result in stable stratification over nearshore waters, even for onshore flow (Small et al. 2008; Wang et al. 2018; Shutt and Seim 2020). In concordance with the expected seasonality of offshore stratification for a site with a complex coastline off Massachusetts, Archer et al. (2016) found that the relative occurrence of unstably stratified boundary layers is greatest during autumn and winter, as cold continental air advects over a warmer ocean. The instability is especially intense during winter cold air outbreaks when polar continental air overruns a much warmer ocean (Grossman and Betts 1990; Field et al. 2014).

The effect of stratification on offshore wind profiles is demonstrated in Fig. 4, which shows wind profiles obtained from 12months of data collected by a buoy-based lidar system $114 \mathrm{~km}$ off New Jersey, a region likely to see significant future wind energy development. The description of the location and data are provided in Debnath et al. (2020). The data set is partitioned into separate averaged profiles dependent on the difference between the 2-m air temperature and the SST $(\Delta \mathrm{T}=\mathrm{T} 2 \mathrm{~m}-\mathrm{SST})$. For strongly unstable stratification, suggested when $\Delta \mathrm{T}<-2 \mathrm{~K}$, the vertical wind shear is small; for nearer-neutral stratification, the shear is moderate; and for strongly stable stratification (suggested when $\Delta \mathrm{T}>2 \mathrm{~K}$ ), the shear is very large, with the mean wind speeds at $200 \mathrm{~m}$ reaching nearly $22 \mathrm{~m} / \mathrm{s}$. As suggested by Debnath et al. (2020), strong synoptic pressure gradients and associated temperature advection are required to maintain very stable stratification over the ocean. These pressure gradients drive strong winds, which are further enhanced above the surface owing to the reduction of friction by the stratification. The percentage of time that each category was observed was $33 \%$ strongly unstable, $36 \%$ weakly unstable, $28 \%$ weakly stable, and $2.8 \%$ strongly stable. 


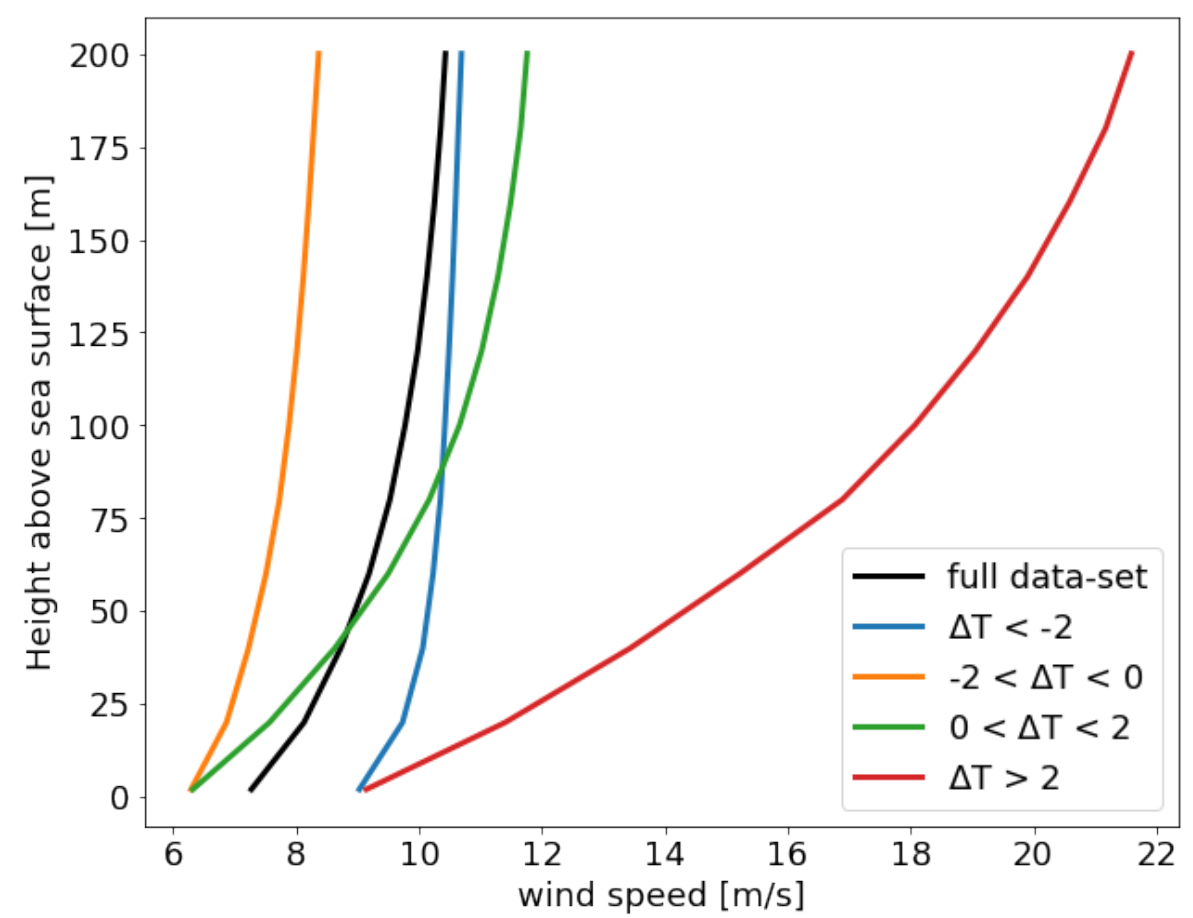

Figure 4: Vertical profiles of mean wind speed calculated from 12-months of buoy-based lidar observations, for four different categories of $\Delta T=T 2 m$ - SST. Temperature differences are in K. (From Debnath et al. 2020).

Another complicating factor for predicting winds in the offshore stable ABL is that these ABLs are often accompanied by lowlevel jets (Mahrt 1999; Mahrt et al. 2014; Colle et al. 2016, Pichugina et al. 2012, 2017; Banta et al. 2018). Figure 5 shows an example of a low-level jet (LLJ) derived from the same buoy lidar measurements taken off New Jersey - a high wind shear case presented in Debnath et al. (2020). The top panel of the figure shows a 2-day time series of wind speed at 20-m height intervals up to 200-m AGL, while the bottom panel shows the corresponding SST and 2-m air temperatures. The spread of the wind speeds (indicative of wind shear) starts off small at the beginning of the time series when the air-sea temperature difference is small, then increases to a very large spread as stable stratification develops with the air temperature warmer than the SST. At the end of the time series, the shear again decreases as the air-sea temperature difference becomes smaller. The middle panels of the figure show vertical wind speed profiles averaged over two periods with stable stratification, the first when a low-level jet is present with a wind speed maximum at about 100m AGL. The jets can be extremely sharp, with maxima occurring at heights within or even below the rotor plane for offshore wind turbines. The second profile occurs during a period with similar stable stratification, but demonstrates a strong monotonic shear. 
https://doi.org/10.5194/wes-2021-156

Preprint. Discussion started: 21 February 2022

(c) Author(s) 2022. CC BY 4.0 License.
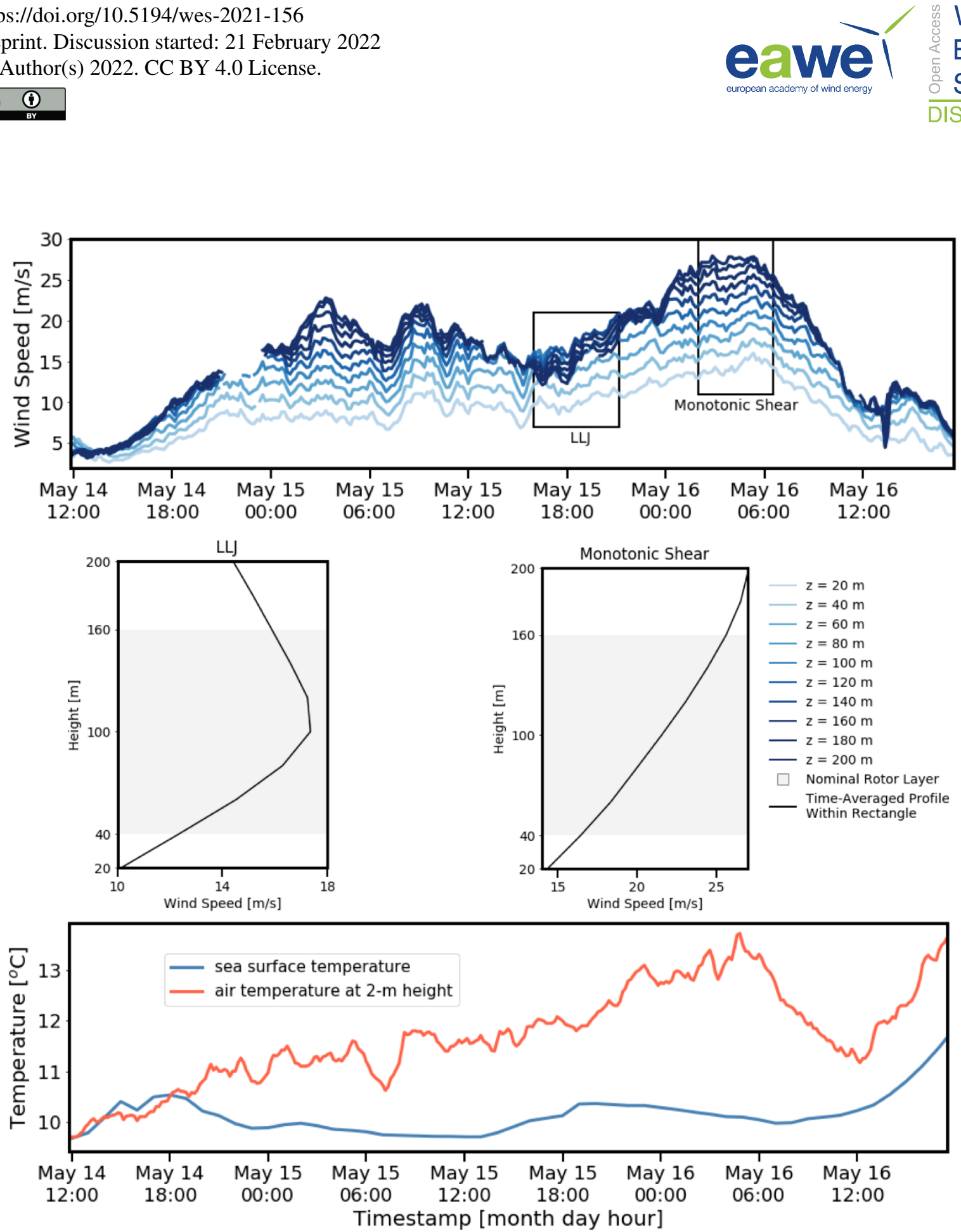

Figure 5: A high-shear wind event measured by a floating lidar deployed within the wind lease areas of New Jersey coast (top). The middle figure provides the time averaged wind speed profiles of the black boxes shown in the top figure. The SST and air temperature at 2-m height measured at the same location are provided in the bottom figure. (From Debnath et al. 2020).

Although the suppression of turbulence by the vertical temperature gradient in the stable boundary layer allows for LLJs to keep from being mixed out and for strong shears to be maintained, the surface horizontal temperature gradient (baroclinicity) can be important for determining the strength and height of the LLJ (Helmis 2013; Mahrt et al. 2014). This baroclinicity can result not only from synoptic scale weather systems, but also from land-sea temperature differences and gradients in SSTs, 
including those caused by coastal upwelling and the presence of the Gulf Stream. These baroclinically-driven near-coastal jets can then be influenced by inertial effects and by complex coastlines and associated topography (Burk and Thompson 1996). The resultant winds can subsequently modify the SSTs, which can then lead to a further adjustment of the winds in a complex feedback process. An example of locally driven coastal winds and their impacts on SSTs is provided by Hong (2009), who found large amplitude, small spatial scale SST variability $\left(6^{\circ} \mathrm{C}\right.$ over $\left.5-10 \mathrm{~km}\right)$ in the area south of Martha's Vineyard that was linked to highly spatially variable coastal winds associated with the complex coastline. The magnitudes of these SST gradients were observed to change significantly on the time scale of a day.

Physical processes that control ABL stratification include temperature advection and its variation with height, the surface heat flux, subsidence, and entrainment at the top of the boundary layer. In addition, radiative flux divergence can be important, especially in ABLs that contain fog or boundary layer stratus clouds, which often are present in very stably stratified conditions. Coastal fog or stratus can also advect onshore to varying distances and, by doing so, reduce overland heating in the daytime, consequently altering the development of sea breeze flows.

Measuring stratification itself, as well as the controlling physical processes of temperature advection, surface heat flux, subsidence, entrainment, and the radiative flux divergence, both offshore and in the coastal zone, is a daunting challenge; longterm observations of these quantities are largely missing in the difficult offshore environment. Temperature and wind observations through the depth of the boundary layer and the entrainment processes at the top of the ABL will certainly require some type of remote sensing approach, perhaps using a combination of coastal, island, and buoy deployments. For shorterterm intensive observation periods, aircraft, unmanned aerial systems, and ship- or barge-based platforms would be useful. Given the myriad forcing mechanisms affecting coastal ABL stratification and LLJs, it is not surprising that they are difficult 375 to simulate accurately (Jiang and Edson 2020). Simulating, including forecasting, these conditions is challenging for multiple reasons. First, forecasting the stable boundary layer is more difficult in general than forecasting the neutral boundary layer, even over land. Small variations in model initial conditions, including spatial gradients, can result in low-level jets with significantly different structure and boundary layer shear. Second, boundary layer parameterizations are less well understood and less constrained by observations for strong stratification, either stable or unstable. As one example of the first issue,

380 Shimada (2015) showed that having accurate, high-resolution SST data sets that resolve near-coastal variability is important for reducing errors in the estimation of annual average wind speeds, and for reducing model forecast root mean squared error (RMSE), with a $3^{\circ} \mathrm{C}$ difference in SST causing an approximate $6 \%$ difference in the wind energy density at a height of $80 \mathrm{~m}$. Having the ability to run numerical weather prediction models with high spatial resolution SSTs is necessary for wind resource estimation, and having the ability to run coupled atmosphere-ocean models that can resolve rapidly evolving coastal SSTs seems a necessity for wind energy forecasting (discussed further in Section 5). 


\section{Wind shear and turbulence in the rotor layer}

Unsteady characteristics of wind speed due to various atmospheric phenomena add complexity to wind power generation and reliability (Wagner et al. 2011; Murphy et al. 2020). Ambient turbulence modulates the mixing of the wind inside a wind farm. In this way, the ambient turbulence influences the overall power production from a wind farm and the fatigue loads on the turbines (Wu and Porté-Agel 2012). For example, low ambient turbulence energy contributes little to no mixing of highermomentum air aloft into the wind plant. This slows the recovery of flow in individual turbine wakes and can thus reduce the overall power production of a wind farm. Conversely, high ambient turbulence accelerates the mixing of wind and facilitates power production, but increases the load on the turbines.

Turbulent wind fluctuations govern the aerodynamic performance of wind turbine blades. The rotating blades add turbulence

395 to the wind as they extract energy, and this turbulence can subsequently propagate throughout the wind farm and substantially increase the wind load on the downstream turbines (Frandsen 2007). Depending on the ambient turbulence and turbine operating conditions, the blades add different levels of turbulence energy to the downstream wind (Magnusson and Smedman 1994; Crespo and Hernández 1996; Chamorro and Porté-Agel 2009). Understanding ambient wind conditions is therefore necessary to accurately assess the expected lifetime of the turbine blades and the power performance of the wind farms.

400 The unsteady characteristics and variation of wind with height are conventionally expressed in terms of commonly used variables, such as wind shear, wind veer, turbulence intensity, TKE, and wind coherence. The behavior of these key variables at rotor heights is connected to a wide variety of meteorological phenomena, such as land-sea circulations, wave-atmosphere interactions, synoptic scale events, and coastal topography, in ways that are not fully understood. These different offshore phenomena create large variations in the wind characteristics and ultimately add uncertainty in the wind plant load and power

405 performance calculations.

Offshore wind turbines are larger in diameter than onshore turbines, with current diameters ranging from $120 \mathrm{~m}$ to $220 \mathrm{~m}$ (IRENA 2019; GE Renewable Energy 2019, Gaertner et al. 2020), and the shear and veer within the boundary layer will have significant impact on the offshore turbines and their performances (Murphy et al. 2020). Stable stratification has a notably large impact on such large rotors. The stable ABL generally contains weaker turbulence and lower boundary layer heights together with higher wind shear and veer. Within very shallow boundary layers, the turbine blades can plausibly intersect both the surface layer and top of the ABL. At the lowest point of each rotation, blades may intersect the surface layer. At the top, blade tips may encounter the nose of an LLJ or pass through the boundary layer top, thus covering almost the whole ABL within the rotor-swept area. The resulting variation of turbulence, wind shear, and veer within such a large rotor layer can add significant loads on the turbine blades and gearbox components, thus shortening the life of blades and gearbox components

415 (Lee et al. 2013). Under these conditions, simple power laws or log laws do a poor job of describing the shear and veer conditions encountered by wind turbines. Moreover, there are no other analog functions available for these variables. Validating the ability of numerical models to reproduce the shear, veer, and turbulence in the rotor-swept area for the range of 
https://doi.org/10.5194/wes-2021-156

Preprint. Discussion started: 21 February 2022

(c) Author(s) 2022. CC BY 4.0 License.

\section{(c) (i)}

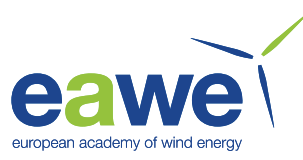

offshore conditions with sufficient accuracy to satisfy turbine engineering and operational needs remains a major challenge for offshore wind energy.

The joint occurrence of shallower boundary layers and low turbulence also results in persistent turbine-induced wakes, which can reduce the power production of downstream turbines within wind plants. Wind turbines extract momentum from wind, producing wakes that propagate downstream and reduce the power production from subsequent turbines. The availability of the wind resource for the downstream turbine is dependent on the recovery of the wake generated by the upstream turbine, and the recovery of the wake is dependent on the mixing and interactions of wake with surrounding ambient wind. If the incoming wind turbulence is low, wakes from the individual turbines persist longer. This in turn reduces the wind resource for the next row of turbines, thus reducing the overall power production from the wind plant (Lundquist et al. 2018; Porté-Agel et al. 2020; Platis et al. 2018). Lundquist et al. (2018) also showed that if the turbulence intensity is low, the aggregate wake from a wind plant can persist up to $40 \mathrm{~km}$ downstream. This could substantially influence the planning and design of offshore wind plants. There are different wind turbine control strategies to manage the wind turbine wake and improve the performance of the wind plant power. The common strategies are wake steering (Fleming et al. 2017, 2019), consensus control (Wang et al. 2018, Gionfra et al. 2017; Annoni et al. 2018), dynamic induction control (Steinbuch et al. 1988; Dilip and Porté-Agel 2017; Munters et al. 2018; Wang et al. 2020), and wake steering with induction control (Bossanyi 2018). Even the control strategies are dependent on the atmospheric conditions showing significant power gain in stable ABL and minimal power gain in unstable ABL (Fleming et al. 2017, 2019). Thus, an accurate prediction of both height and time variation of the wind (e.g., wind shear, wind veer, turbulence intensity) is important to wind energy applications.

Besides time and height variation of wind, offshore wind faces a significant horizontal variation of wind due to the spatial variation of SST and different marine atmospheric phenomena (Edson et al. 1999, 2007; Wang et al. 2018). Considering the large diameter of offshore wind turbines, the spatial variability of wind and coherent structures could introduce more load on the turbines (Velarde and Bachynski 2017; Wise and Bachynski 2020). The wind industry uses hub height turbulence (e.g., turbulence intensity) of the wind flow to estimate the wind loads on turbines. In addition, the class of wind turbines (IEC 2019) for a project is chosen based on the turbulence intensity at the site. The proper selection of turbine classes for a project directly influences the outcome of the project investment. In summary, the cost of offshore wind energy is highly controlled by the wind turbulence (Mora et al. 2019).

Another important aspect of offshore wind turbulence is its interaction with the rotor, and thereby its implications for a turbine's power and load fluctuations. A number of recent studies have shown that the rotor acts as a low-pass filter to incoming turbulence (Chamorro et al. 2015; Tobin et al. 2015; Anvari et al. 2016; Deskos et al. 2020). That is, when large, energetic, turbulent structures pass through the rotor, they will yield bending moment and shaft torque fluctuations at a similar frequency and magnitude, while smaller structures will have a smaller effect, apart from the blade-passing frequency and its higher harmonics, in which case the amplitude of the load will resonate with the rotating blade. The spectral distribution of bending moment and torque fluctuations are inherently related to blade and main shaft bearing fatigue and may lead to premature failures of these components. On the other hand, in turbine clusters (arrays), resonant modes are the result of a canonical 
turbine spacing (equal spacing in each direction) and their spectral signature can be detected in the power and load spectra at much lower frequencies. Recent analysis of the power fluctuations of laboratory-scale and real-scale wind farms has shown that a time scale $\mathrm{S} / \mathrm{U}$, where $\mathrm{S}$ and $\mathrm{U}$ are the spacing and velocity magnitude in the dominant wind direction, is the main parameter that shapes the power spectra (Bossuyt et al. 2017; Lukassen et al. 2018; Seifert et al. 2020). However, the origin of offshore wind plant-aggregate power fluctuations is much more involved, and many environmental factors — such as changes in wind speed or wind direction, influences from neighboring wind farms, or their own state of operation (Seifert et al 2020) may play an important role. Nonetheless, such wind plant-wide fluctuations may create challenges for grid stability, particularly in the offshore environment; therefore, additional investigation may be required.

Low frequency large-scale structures or high frequency small-scale structures both are important in power production and fluctuation, as well as load on the turbine blades and gearbox components, and, ultimately, add uncertainty to the forecasted power that will be added to the power grid.

Numerical models such as the Weather Research and Forecasting (WRF) model can provide spatial variability of wind and profiles throughout the marine ABL influenced by the synoptic, mesoscale, and microscale processes. However, the WRF model often poorly represents turbulent parameters such as the friction velocity and sensible heat flux and exhibits errors in offshore wind resource assessments due to different mesoscale and microscale forcings as well as sea surface interactions. Numerical weather prediction models provide estimates of TKE rather than turbulence intensity, but these calculations remain largely unvalidated with observations offshore. The numerical models need to have better predictability a priori for offshore wind farms to save cost of repair in marine environments.

\section{Modeling the marine atmospheric boundary layer}

\subsection{Overview}

Many different types of models have been used by the engineering and scientific communities to characterize metocean conditions, as well as conduct offshore wind resource assessments, site selection, and individual turbine and wind farm design and optimization studies (Kalvig et al. 2014; Veers et al. 2019). Yet, there are remaining challenges in modeling the offshore environment that still require significant research efforts to be made. Compared to its land-based counterpart, the marine ABL poses additional challenges from a modeler's point of view, thanks to the presence of air-sea interactions that comprise several physical processes spanning multiple orders of magnitude both in temporal and spatial scales (Sullivan and McWilliams 2010). Traditionally, atmospheric models have been split into two main categories based on their ability to resolve ranges of scalesmesoscale (10-1,000 km) models and microscale models (less than $1 \mathrm{~km}$ ). Mesoscale models are relevant to offshore wind resource assessment whereas microscale models attempt to better couple wind and waves and more accurately describe the mass, momentum, heat, and humidity exchange at the air-sea interface. From an offshore wind energy point of view, microscale models can potentially be used to obtain structural loads and power output under both operational and extreme weather conditions. Structural load assessment of extreme and non-operational conditions poses an additional challenge, as the 
modeling approach should account for the coupled influences of the changing wind, wave, and current fields throughout their evolution (Kim et al. 2016). Even under normal operational conditions, technical modeling challenges arise from the presence of combined aero- and hydro-dynamic loading effects and the modeler's ability to predict the life cycle fatigue load spectrum. This may require accurately predicting the directional wave spectra in addition to characterizing the available wind resource. Because of the nonlinearities associated with the aerodynamics and hydrodynamics, the simulations are typically run in the time domain. To that end, extrapolation techniques are needed to capture the full range and duration of all the stochastic loading from wind and waves, often in a coupled fashion (Butterfield et al. 2007). An additional complexity in offshore wind energy applications is that the presence of turbine rotors and other supporting structures affects the marine ABL (see Figure 2), creating atmospheric wakes, potentially triggering gravity waves, as well as impacts via coupling with hydrodynamics in case of floating structures.

\subsection{Current state-of-the-art modeling practices}

\subsubsection{Microscale models}

Microscale models can be divided into two main categories - the wave-phase-averaged and the wave-phase-resolving models (Deskos et al. 2021). Wave-phase-averaged models consider empirical bulk formulae to compute interfacial stresses based on quantities such as wave age (Donelan 1990; Smith et al. 1992; Fairall et al. 2003; Oost et al. 2002), measures of sea spray (Liu et al. 2011), significant wave height and length (Warner et al. 2010; Geernaert et al. 1986, 1987; Geernaert 1990; Smith et al. 1992; DeCosmo et al. 1996; Taylor and Yelland 2001; Foreman and Emeis 2010; Jiménez and Dudhia 2018), or 2-D wave spectra (Wu et al. 2019). On the other hand, wave phase-resolved simulations (Yang et al. 2013; Sullivan et al. 2008, 2014, 2018a,b; Hao et al. 2018) resolve both the airflow turbulence and the phase of the underlying waves. To this end, phaseresolved models need to combine two models to resolve the flow within the wave boundary layer and thereby accurately capture the momentum and scalar quantities flux transfers (upward or downward) between the wind and waves. The model coupling comprises exchanging velocity, pressure, and free surface elevation at the air-sea interface. The two models use different assumptions for the flow field; the wave propagation is often described through potential flow theory with nonlinear free surface dynamic boundary conditions, while the airflow is described via the incompressible Navier-Stokes equations. Wave phase-resolved simulations represent the highest fidelity models and exhibit computational limitations due to their increased need for resolution and inherent algorithmic complexity. To this end, they are often used to study the fundamentals of wind-wave interaction or to inform models and correct existing drag law models (e.g., Andreas et al. 2012) about the wave age parameter (Sullivan et al. 2014) or swell direction (e.g., in the WRF model as in Patton et al. 2019). One question arising from the use of wave phase-resolved simulations is whether two-way coupling between the two models is needed. It can be argued that the time scales characterizing the evolution of wind waves are disparate with waves growing much slower than the evolution of the boundary layer eddies, and therefore two-way coupled simulations may be beneficial for simulations of 
winds without dissipating. To this end and for short-term forecasts, a one-way coupling approach (from the waves to the wind) is often preferred (Deskos et al. 2021). It is worth noting, however, that when wind-wave interaction between steep waves with strong-wind forcing is considered, which leads to intermittent wave breaking, the above-described loose coupling breaks down, and thus a two-phase flow approach may be needed. Events such as wave plunging may have a substantial impact on the turbulence statistics and flow structures near the wave surface, with time scales comparable to the wind eddy turnover time scale (Yang et al. 2018).

\subsubsection{Mesoscale models}

Atmospheric and ocean circulation patterns have large scales in both space (10-1,000 km horizontally) and time (hours to weeks), therefore, mesoscale models are required to characterize the atmospheric and oceanic "weather" conditions and sea state entering the offshore wind farm region. The charge of modeling ocean wind waves at these scales is particularly challenging because whereas waves are driven by the mesoscale weather, individual waves have periods on the order of seconds and wavelengths on the order of meters. This otherwise computationally prohibitive challenge is removed by using phase-averaged spectral wave models that simulate the integrated wave energy spectrum instead of the time-space evolution of the sea surface elevation (Pringle and Kotamarthi 2021). Specific phase-averaged spectral wave modes most commonly used for wind-wave coupling are the WAVEWATCH III (WW3; WW3DG 2019) and the Simulating Waves Nearshore (SWAN; SWAN team 2020) models. Due to the mesh type and numerical implementations of each model (c.f. Pringle and Kotamarthi 2021), traditionally WW3 is used for global and regional simulations whereas SWAN is used for high-resolution simulations in a local region including the nearshore area. Recent developments for handling unstructured meshes and implicit time stepping in WW3 mean that it can now be efficiently applied to simulations across a range of scales, including the nearshore area, in a single model (Abdolali et al. 2020a,b).

To properly characterize the mesoscale weather conditions in the marine ABL for an offshore wind farm requires accounting for the interaction between the atmosphere and the ocean, as represented by separate models for the wind, ocean currents, and waves. A number of so-called coupled atmosphere-wave-ocean modeling systems have been developed in the last one to two decades (e.g., Chen et al. 2007; Liu et al. 2011; Warner et al. 2010; Zhang et al. 2009; Li et al. 2019; Wu et al. 2020). They

540 have typically been developed with a primary focus on tropical cyclone research and prediction that can be utilized for such extreme conditions that are encountered offshore of the U.S. Atlantic coastline. However, coupled models such as the Coupled Ocean-Atmosphere-Wave-Sediment Transport modeling system (COAWST; Warner et al. 2010), the Uppsala University Coupled model (UU-CM; Wu et al. 2019), and the Chemical Hydrological Atmospheric Ocean Wave System (CHAOS; Varlas et al. 2018) are now being used to characterize the offshore wind energy resource. Results from the North and Baltic Seas generally indicate that under low to moderate wind speeds, model coupling will provide lower estimates (order of $10 \%$ ) of offshore wind power density than an uncoupled atmospheric model, whereas there is a negligible difference for higher wind speeds (Pringle and Kotamarthi 2021). 
https://doi.org/10.5194/wes-2021-156

Preprint. Discussion started: 21 February 2022

(c) Author(s) 2022. CC BY 4.0 License.

\section{(c) (i)}

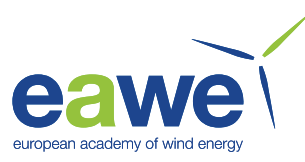

Implementing coupled atmosphere-wave-ocean modeling systems involves linking the individual models through coupling toolkits (e.g., Jacob et al. 2005; Larson et al. 2005; Craig et al. 2017) that interpolate and exchange the pertinent interfacial quantities, such as surface wind velocities, SST, and significant wave heights. Within these coupled modeling systems, the determination of the interfacial air-sea fluxes is one of the most important considerations, which depends on sea surface roughness (waves), SST and velocity, and the effects of sea spray and wave breaking. A number of empirical bulk formulae have been used to parameterize these fluxes with a particular focus on the sea surface roughness aspect, typically based on either wave steepness (Warner et al. 2010; Geernaert et al. 1986, 1987; Geernaert 1990; Smith et al. 1992; DeCosmo et al. 1996; Taylor and Yelland 2001; Foreman and Emeis 2010; Jiménez and Dudhia 2018) or wave age (Donelan 1990; Smith et al. 1992; Fairall et al. 2003; Oost et al. 2002; Patton et al. 2019), which indicates whether the waves are being driven by the local winds and growing (a young sea) or whether the waves are mostly old swell waves that are propagating from a far-field location. An additional consideration is accurate resolution of SST variability, which, as described in Section 3, can impact both mesoscale and microscale flow parameters of relevance to offshore wind energy.

\subsection{Opportunities for improving the modeling of the marine ABL}

As we mentioned above, both microscale and mesoscale models provide solutions that can be used to resolve different scales and account for different physical processes. However, there are still pathways and opportunities in the pursuit of improving the current offshore wind energy modeling capability. This includes individually improving existing microscale and mesoscale models; their coupling, also known as meso-microscale coupling (MMC); and the introduction of new algorithms, either physics-based or data-driven, to existing high-fidelity models. Finally, another avenue for improving existing capabilities, although tangential to the modeling efforts, is the refactoring of existing codebases in order to be ported to future exascale high-performance computing (HPC) systems.

Starting with the microscale models, and in particular the wave-phase-resolved simulations, a number of challenges remain regarding the representation of the wall-shear stress model atop moving waves (Yang et al. 2013), as well as the incorporation of wave breaking, air entrainment in existing LES models. Wave breaking and slamming during extreme weather conditions, especially in shallow coastal waters, necessitates the use of phase-resolving wave models, while also considering the complex interface with the atmosphere and the effects of sea spray (Richter and Sullivan 2013). In lieu of physics-based models that can incorporate such complex behavior, ML-based wall-stress models can offer an alternative pathway. Other important topics for future research include modeling of subgrid-scale phenomena, small wavelength wind-driven waves, and smaller scale turbulence occurring within the wind turbine wake region. Similarly, mesoscale models can adopt wave-informed drag models that account for different air-sea interaction phenomena, such as wind-wave misalignment (Patton et al. 2019), variable SST boundary conditions, and, potentially, wave breaking.

On improving the MMC modeling aspect of wind-wave interaction, using SWAN or WW3 to generate wave boundary conditions for microscale models may also require an interface between the mesoscale and microscale models. To this end, microscale models will require an accurate prescription of inflow conditions that mimics all relevant characteristics of the 
atmospheric and oceanic fields, such as the sheared velocity profile, the anisotropy of the turbulence, and the nonstationary nature of the inflow (Sanderse et al. 2011). The effects of highly variable inflow are known to have a nontrivial influence on fundamental aerodynamic characteristics of the airfoil (Veers et al. 2019). Therefore, overly simplified inflow conditions can lead to significant errors. In the metocean environment, the inflow sea state is also critical. This is commonly described by a particular spectrum (e.g., JONSWAP) with a given significant wave height and peak spectral period (Sebastian and Lackner 2012). However, further research is required to truly understand the effects of different sea states and breaking/non-breaking waves on atmospheric wakes at the rotor layer.

Both microscale and mesoscale models will be greatly benefited by their portability to modern HPC systems, in particular those using GPUs, which will provide significantly enhanced computational throughput. An additional pathway for improvement is the use of higher-order numerical schemes, which not only afford higher accuracy for the same number of mesh nodes, but also provide higher scalability and parallelization of the simulation codes in the upcoming exascale computing systems, such as Summit, Aurora, and Frontier at U.S. Department of Energy laboratories. The systems that will be coming online within this decade (2020-2030) rely heavily on GPUs for performance and require substantial refactoring of the implementation of existing codebases. Existing examples of microscale codes that have been refactored to become GPU-ready

595 to take full advantage of the next HPC frontier include nekRS (Fischer et al. 2021), amr-wind (Sprague et al. 2020), and FastEddy® (Sauer and Munoz-Esparza 2020).

In addition, there is need to improve data assimilation (DA) methods for offshore wind energy applications. The initial conditions of the model are extremely important, especially for the short-term (hours to days) forecast length. The value of assimilation for wind computations at turbine heights offshore has been demonstrated, for example, for wind profiling radar data (Djalalova et al. 2016). However, because of the interaction between the atmosphere and ocean, a coupled DA approach that initializes both the atmosphere and the ocean states is desirable (e.g., Zhang et al. 2020). It is unclear whether a strongly coupled DA approach, which would produce a balanced set of initial conditions for both the ocean and atmosphere simultaneously (e.g., Frolov et al. 2016), or a weakly coupled DA approach, which initializes the atmosphere and ocean separately (e.g., Browne et al. 2019), would be better. From an abstract point of view, it would seem that the former would provide more optimal initial conditions for the forecast model; however, strongly coupled DA systems are inherently more complex than weakly coupled DA approaches and require colocated observations of the ocean state (including subsurface profiles) and the atmosphere (e.g., Tang et al. 2020). Regardless, any coupled DA method requires observations of the atmosphere and ocean states over and beyond the spatial domain of interest, especially as initial conditions well outside the domain can influence longer forecasts.

\section{Impacts of precipitation}

The impacts of precipitation to wind turbine blades potentially cause damage at the leading edges, typically at the outer onethird of the blades. Here, the blades travel through the air mass with high speed (Keegan et al. 2013, Slot et al. 2015). The 
https://doi.org/10.5194/wes-2021-156

Preprint. Discussion started: 21 February 2022

(c) Author(s) 2022. CC BY 4.0 License.

\section{(c) (i)}

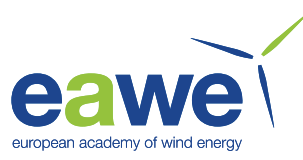

hydrometeor particles hitting the coating material may initiate a progression of changes from initial incubation thru to erosion (Dashtkat et al. 2019). The processes are not well known, but it appears evident that higher tip speed worsens the problem.

615 The erosion is initiated near the tip and grows inward along the leading edge, based on observations are from turbines in an offshore wind farm (Eisenberg et al. 2018). Similar results are reported from accelerated tests in rain erosion test facilities (ASTM 2012; Bech et al. 2018).

Knowledge of the drop size and phase of the particles, either liquid or solid, is important for predicting the erosion processes. Liquid precipitation in the form of rain is generally most abundant, but even brief hail events can cause significant damage (Letson et al. 2020a). A hailstone is by definition larger than $6 \mathrm{~mm}$ in diameter, and therefore larger than most raindrops (although raindrops occasionally can be larger). Rainfall drop size distribution varies with weather type (e.g., stratiform rain is characterized by smaller drops while convective showers are characterized by larger drops). Interestingly, during high wind speeds, the tendency is that raindrops break up and the size distribution changes (Tilg et al. 2020b). For leading edge erosion, it is the rain events occurring during high wind speeds that are of particular interest. Wind turbines operate with high rotational speed during high winds; hence, the tip speed is high. The closing velocity between hydrometeors and turbine blades is a combination of the speed of the blade, the drop fall velocity, and the angle of attack. The tip speed is an order of magnitude larger than the drop fall velocity and is therefore the most important variable (Keegan et al. 2013). The impact kinetic energy is a function of speed and mass of the particle.

The main challenge in predicting the leading-edge erosion process at a given site is the sparse knowledge on rain amount and drop size distribution, in particular in offshore locations. It is not (yet) custom to observe drop size and rain rate at wind farm tender areas or at existing wind farms. Observations of rain during high winds suffer from known bias (under catch), as only a fraction of the falling rain is captured in the rain gauge. Therefore, rain gauges are often located at slightly sheltered sites. Another challenge is to establish a sufficiently long time series to describe the characteristics of the occurrence of wind speed and rain rate jointly. In particular, the high-end tail of the joint distribution of high wind speed and high rain rate is often undersample in short-term data sets. Statistics on extreme wind speed as well as extreme rain events call for long consistent time series to provide reliable statistics. A study using over a decade of weather station data in Denmark at 10-min resolution revealed that high rain rates never occurred during high wind speed events at two inland stations, while at all five coastal stations high wind speed and high rain rate occur jointly (Hasager et al. 2020). Expanding the study to longer time series and more meteorological stations indicates that 10 years of data are needed to estimate the lifetime (Hasager et al. 2021).

640 The coastal and marine environments may be more detrimental than onshore conditions to turbine blades. This may, in part, explain why unexpected repairs at several offshore wind farms have been carried out (Herring et al. 2019). In addition, as offshore turbines grow in size, a given rotational speed will generate higher tip speeds, resulting in greater erosion (Keegan et al. 2013).

The mitigation strategies for leading edge erosion take two routes. The first is to develop coatings that are resistant to rain erosion (Dashtkar et al. 2019; Herring et al. 2019) and to repair blades with degraded coatings more quickly (Mishnaevsky 2019). While the latter is common practice for offshore sites, repair is costly. It can be difficult to find suitable weather 
https://doi.org/10.5194/wes-2021-156

Preprint. Discussion started: 21 February 2022

(c) Author(s) 2022. CC BY 4.0 License.

\section{(c) (i)}

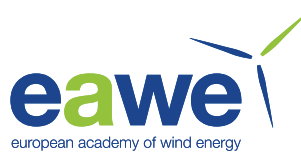

windows, as some coatings require particular temperature and humidity ranges and time for curing. Furthermore, to predict when the next repair is necessary is a challenge without prior knowledge on the leading-edge erosion processes and the wind and rain climate at the site.

The second mitigation strategy is to slow down the turbines during heavy rain events to prolong the lifetime before repair is needed. The turbines should still be in operation, but with lower revolutions per minute (Bech et al. 2018). The method is called erosion-safe mode operation. During hail events, standstill may be safest. Several aspects need to be taken into account before the cost benefit of erosion-safe mode operation for a wind farm owner is clear. First, the loss in energy production during periods slowing down turbines due to heavy rain should be considered. If this happens during times with low electricity market prices, not much earning will be lost. In this case, the spot market price is high, and it might be relevant to operate with only a little slow down or short interval with over torque. Second, operating the turbines with eroded blades will cause a loss in annual energy production of a few percent (Bak et al. 2020). Third, the cost of repair and the downtime during repair has to be considered. An optimization of the parameters is presented in Skrzypiński et al. (2020) and shows profit for owners. To implement erosion-safe mode operation, rain detection at sufficient temporal and spatial resolution is suggested. One candidate measurement technology for this purpose is to deploy a micro rain radar near the turbines (Tilg et al. 2020a).

In summary, the challenge of predicting leading edge erosion at sites is to ensure reliable and representative observations. These data could be from disdrometers observing the drop size distribution (Kathiravelu et al. 2016). In the offshore environment, precipitation observation from Earth Observing satellites, such as the Global Precipitation Measurement mission (Huffman et al. 2014; Rios Gaona et al. 2016), may be an option to prepare wind and rain statistics relevant for leading edge erosion. More specifically, the drop size distribution from the Global Precipitation Measurement mission (Minda and Chandrasekar 2014) may be relevant for leading edge erosion. Validation of the satellite-based rain products would be useful and characterization of drop size distribution with high temporal resolution based on in situ observation concurrent with wind measurements would be ideal. A ground-based radar network is an alternative source of information to provide offshore coverage (Fairman et al. 2017). These observations will be affected by scattering off the turbine blades, however (e.g., Norin 2015). Again, local observations in the offshore environment are necessary to provide reliable rain statistics.

Modeling the wind and rain using numerical weather prediction models is an option for characterizing the precipitation erosion environment. Global-scale and limited area models using horizontal grid spacings of greater than a few kilometers generally lack the ability to represent precipitation characteristics of relevance to leading edge erosion, either relying on simplified microphysical treatments, or in some cases using superparameterizations (e.g., Khairoutdinov et al. 2005) or other approaches to provide higher-fidelity microphysical information that is then aggregated back to the coarse model mesh. However, models employing grid spacings of a few kilometers or less can employ much more sophisticated bulk or spectral (bin) microphysical parameterizations, or combinations of those approaches, each of which can predict relevant microphysical processes and precipitation characteristics at the scale of the individual cloud or smaller. Many such schemes are available within community atmospheric models, such as WRF, and have been evaluated in storm events featuring heavy precipitation, including supercell 
thunderstorms, squall lines (which comprise the dominant mesoscale convective storm morphology in offshore environments), or tropical storms and hurricanes (Khain et al. 2015).

Prediction of the raindrop size distribution requires at least the complexity of a two-moment bulk scheme, which independently evolves the mass mixing ratio and mean drop size (whereas single-moment schemes predict only mass mixing ratio), but makes assumptions about the shape of the size distribution. While bulk schemes only predict the number and mass-weighted mean drop fallspeeds, the fallspeed can be calculated offline using the scheme's fallspeed-size relation. Bin schemes, which predict cloud parameters in discrete size intervals, evolve the drop size distribution shape explicitly, as well as calculating the fallspeed in each size (or mass) bin (Morrison et al. 2020). Comparisons among single-moment, higher-moment, and bin schemes (Khain et al. 2015) generally conclude that higher-moment bulk schemes and spectral bin schemes provide superior performance to one-moment schemes in WRF and other models in heavy precipitation events, and specifically squall lines (e.g., Khain and Lynn 2009; Li et al. 2009a,b; Morrison et al. 2009; Baldauf et al. 2011). Treatment of hail is also possible with higher-moment bulk and bin schemes, with several studies indicating that a three-moment representation of the hail particle size distribution is required to accurately predict hail larger than a couple of centimeters in diameter (Loftus and Cotton 2014; Milbrandt and Yau 2006)

Letson et al. (2020b) have investigated output from the WRF model on hailstorms for leading edge erosion for a short period

695 of less than one month. Further investigation of the efficacy of more sophisticated microphysical schemes in WRF and other community models over multiple events and for longer periods is recommended to assess their value relative to their increased computational expense, which can be marginally greater for higher-moment bulk schemes, and significantly greater (one to two orders of magnitude) for bin schemes.

\section{Applications of machine learning}

700 In recent years, a large institutional and scientific interest in the topic of machine learning (ML) has been emerging in the climate and renewable energy disciplines (e.g., Stevens et al. 2020), and rapid advances have been made, as discussed below. The promise of ML lies in the ability to make full use of big data, including those provided by networks of remote-sensing systems and computationally expensive model results. ML can use this data to detect patterns of complex nonlinear phenomena that is typically not feasible using traditional theoretical and empirical analysis. The hope is that this will help further our

705 scientific understanding of the relationship between wind, waves, and turbine wakes within the marine ABL, and provide lowcost surrogate models for a wide range of applications in the offshore wind energy industry.

ML methods, such as neural networks, are well suited to developing functional relationships between inputs and outputs of interest, having been successfully applied to numerous atmospheric physical processes (Wang et al. 2019) to generate new parameterizations, emulate existing ones (e.g., Lagerquist et al. 2021; Gettelman et al. 2021), or even to emulate the physics

710 and dynamics of a simple general circulation model (Scher 2018). Recent advances have been made in ML-based surface layer parameterization to replace the M-O theory-based parameterization by developing ML parameterizations directly from 
observations, and thus avoid the assumptions imposed by the M-O similarity theory (McCandless et al. 2021). Initial results from this study indicate that ML models trained on several years of observations from the Cabauw mast in the Netherlands and from the NOAA's Field Research Division tower in Idaho outperform the M-O theory-based surface layer parameterizations.

In addition to these advances in the onshore environment, the difficulty of obtaining a universal, physics-based understanding and representation of how the air-sea interface impacts flow quantities of interest in the offshore environment may also be mitigated by ML methods (e.g., Dettling et al. 2021). Jiang et al. (2018) achieved a reduction of the error associated with the predicted maximum wind intensity of $60-70 \%$ by using a neural-network-based algorithm to represent typhoon-induced sea surface cooling. In a similar fashion, Bessac et al. (2019) highlighted that sub-grid scale sea surface fluxes are better represented using stochastic Gaussian process models than deterministic bulk flux parameterizations. Other than model parameterizations, ML devices have also been used to directly forecast offshore wind power by training neural network models on metocean reanalysis data (Balluff et al. 2015) or on in situ supervisory control and data acquisition (SCADA) measurements (Lin et al. 2020).

725 Finally, it must be stressed that ML methods require extensive data sets upon which to train, and therefore will require novel and extensive measurements of key input and output variables spanning a range of atmospheric conditions. Long-term observations, under all stability conditions and representative of various offshore regions, will be critical for advancing this field and evaluating how the emerging ML models perform in the representation of complex physical processes in offshore environments. Furthermore, computational models with sufficiently high fidelity (e.g., LES) can also be used to generate data

730 for training of ML approaches. Recently, Fytanidis et al. (2021) showed that flow wakes behind tall buildings could be accurately predicted with a reduced order model trained on LES simulations, and a similar approach could be applied to offshore wind turbine wakes.

\section{Summary and recommendations}

\subsection{Summary}

735 Early in this review, we noted that atmospheric processes affecting winds and turbulence, which in turn modulate the production of energy from wind, span at least five orders of magnitude. In addition, smaller scales become important if processes of FSI are included. Even with modern advances in computing, it is not feasible to resolve all of these scales simultaneously in a single model. A standard approach is to nest models of increasing fine resolution. This requires that unresolved processes be parameterized, however, and current parameterizations are generally scale-dependent and often embody assumptions that are routinely violated, as in classical M-O theory, or are simply not tested over the range of atmospheric conditions to which they are applied. The range of scales and the uncertainty of the some of the physics supporting the subgrid-scale parameterizations make the accurate representation of wind flow into and through wind plants one of the grand challenges of wind energy science. 
The atmospheric sciences grand challenge is enhanced offshore for the following reasons:

- The marine ABL is poorly observed for wind energy, which has severely limited the validation of existing models and the associated identification of specific physics issues in the models.

- Air-sea interaction is a complex process involving nonlinear feedbacks between winds and waves that both modify the wind profile and generate complex physical loads on wind turbine structures.

- Current-driven spatial SST variations often generate stable thermodynamic stratification, which generates complicated layering, wind profiles, and turbulence impacts in the rotor layer.

- The coastal boundary between land and sea generates phenomena such as low-level jets, which are difficult to simulate accurately but are low enough in altitude to significantly affect both power generation and mechanical loads on turbine structures.

- Optimal modeling approaches offshore are currently unclear with respect to the way the ocean and the atmosphere should be coupled for the various time and space scale of interest. Does the ocean mixed layer need to be fully coupled to the marine ABL? Should there be two-way coupling between the waves and the atmosphere, or is one-way coupling sufficient? Can artificial intelligence and ML assist with some of the more troublesome parameterizations?

- Precipitation is a significant contributor to leading edge erosion on wind turbine blades, but our ability to simulate associated drop size distributions offshore is severely limited by the lack of observations of what those distributions actually are.

\subsection{Specific challenges and recommendations}

\subsubsection{Model validation}

There is no substitute for observations in the real atmosphere for validation of atmospheric models, and validating observations need to span a large subset of the conditions to which models will be applied. The marine ABL, however, is a notably hostile environment for making measurements, and there are few stable platforms at sea on which to mount sophisticated profiling instrumentation. Except for satellite observations of clouds and the surface and for surface measurements from buoys, longterm observations of the marine ABL, especially in the rotor-swept area, remain rare.

Recommendations:

- Large-scale, multi-seasonal field studies Validating models that span many scales is most efficiently done with observation sets that also span the simulated scales. The second Wind Forecast Improvement Project (WFIP2; Shaw et al. 2019) was a successful realization of this concept on land, and similar studies are needed in the offshore environment. Such studies are costly and require national-scale investment, but as WFIP2 demonstrated, the payoff can be significant.

- Adaptation of land-based measurement systems for long-term deployment at sea Many important observations, such as surface winds, sea surface temperatures, current profiles, wind profiles, and 
wave spectra, are already routinely available from buoys or other platforms at sea. However, for understanding and advancing model performance offshore, the following additional observations are needed.

○ Remote sensing methods

These methods are currently the most promising path for obtaining key observations above the surface in a cost-effective manner. Motion-correcting Doppler lidar systems are now routinely mounted on buoys and deployed for many months, and these excel at providing wind profiles through the rotor-swept area of wind turbines. However, this only provides wind information to a maximum altitude of about $300 \mathrm{~m}$ above the surface. To understand resource characterization model performance, the following information is also needed:

- Wind vector profiles through the entire depth of the marine ABL and above, as are currently provided on land by Doppler radars and Doppler lidars.

- Profiles of temperature and humidity at least through the depth of the marine ABL, as are provided on land by multichannel infrared and microwave radiometer profiling systems.

- The depth $z_{i}$ of the boundary layer, an important metric for model performance and potentially available from automated measurements with laser-based systems and temperature profiles retrieved from multichannel radiometers.

- Turbulence profiles, derived from lidar- or radar-based systems, adapted for moving platforms at sea.

- Additional observations needed

- Eddy correlation measurements of near-surface turbulence, including temperature and water vapor, to evaluate conditions of validity for classical theories of the atmosphere.

- Drop/particle size distribution observations, such as are made on land via disdrometers, to develop data sets to realistically address turbine blade leading edge erosion.

- Measurements of areal coverage and physical characteristics of breaking waves to relate them to other concurrent observations of air-sea interaction processes and provide input for structural loading models.

\subsubsection{Model improvement}

In conjunction with the fundamental challenge of understanding the physics of key metocean phenomena and processes offshore, the process of modeling itself has specific challenges. One is properly representing the dynamic atmosphere-ocean interface. Non-equilibrium interactions between the two fluids introduces complications, and some preliminary work indicates that direct momentum transfer from the ocean to the atmosphere may modify wind profiles at hub height under some conditions. How to determine when two-way coupling between the atmosphere and the ocean surface may be required and when one-way coupling is sufficient is not clear. A second challenge lies in how to numerically couple fully compressible but 
lower-resolution models of the atmosphere to higher-resolution, incompressible microscale models that allow computation of

wakes and other fine-scale phenomena in such way that the microscale models retain essential fidelity to key atmospheric structure. Related questions include how fine the compressible model's resolution needs to be at the boundary, how best to spin up resolved turbulence in the microscale model, and whether two-way coupling between the atmospheric and microscale models is necessary to properly account for intra-plant and inter-plant wakes offshore.

Recommendations:

- Research into methods to couple atmospheric and microscale models is receiving increasing attention. This work should be continued, including the investigation of two-way coupling, and expanded in the offshore environment, perhaps using coupled models as "hypotheses" to develop validating field studies.

- Systematic investigation of model sensitivities using tools such as uncertainty quantification should be used to focus costly offshore studies. Emerging tools such as ML should also be explored for this purpose.

- New subgrid-scale parameterizations, especially in the atmospheric models, should be developed to address known inconsistencies in currently used parameterizations and to provide important variables, such as drop size distributions, that are currently not available.

- Where the path to improved physics remains unclear, or as an adjunct to improved physical understanding, ML should be used improve the practical value of wind resource characterization modeling.

- New data assimilation methods, especially those that are able to initialize coupled ocean-atmosphere models, need to be developed to better use the available observations to initialize both short-range and medium-range weather prediction models

- Improvements need to be made to both experimental models, such as those used by the community (e.g., WRF), and operational models (e.g., the High-Resolution Rapid Refresh (HRRR); Dowell et al. 2021; James et al. 2021). The latter are especially important, as the operational weather prediction models run by the National Weather Service often serve as foundational forecasts used by the energy community to both integrate wind power into the electric grid efficiently and to make the energy grid more resilient.

Conflict-of-interest statement: The authors declare that they have no conflict of interest.

Author contributions: WS drafted Sect. 1 and 8. JM, PM, JW, and DT drafted Sect. 2. DW, VG, and JW drafted Sect. 3. JW, MD, GD, DT, VG, and RK drafted Sect. 4. CD, WP, GD, and LB drafted Sect. 5. CH drafted Sect. 6. WP, JM, DT, PM, and GD drafted Sect. 7. All authors contributed actively to the editing and review of all sections. 


\section{Acknowledgments}

The genesis of this article lay in the 2019 Workshop on Research Needs for Offshore Wind Resource Characterization supported by the Wind Energy Technologies Office of DOE and in the cited Veers et al. paper on grand challenges in the science of wind energy. We are grateful to the participants in the DOE workshop and in the meetings supporting the grand challenges paper for their stimulating and valuable exchange of ideas. We are also grateful to Sue Haupt, Julie Lundquist, Shannon Davis, Colleen Kaul, Raghu Krishnamurthy, and Chris Fairall for their very helpful comments on early versions of the manuscript. Any remaining flaws, of course, are entirely the responsibility of the authors. C.B. Hasager was supported by IFD grant 6154-00018B. Pacific Northwest National Laboratory is operated by Battelle Memorial Institute for the DOE under Contract DE-AC05-76RL01830. Argonne National Laboratory is a U.S. Department of Energy laboratory managed by UChicago Argonne, LLC under contract DE-AC02-06CH11357. This work was authored (in part) by NREL, operated by the

850 Alliance for Sustainable Energy, LLC, for the DOE, under Contract DE-AC36-08GO28308, with funding provided by the DOE Office of Energy Efficiency and Renewable Energy Wind Energy Technologies. Lawrence Livermore National Laboratory is operated by Lawrence Livermore National Security, LLC, for the U.S. Department of Energy, National Nuclear Security Administration under Contract DE-AC52-07NA27344. NOAA authors were supported by NOAA's Atmospheric Science for Renewable Energy program. The views expressed in the article do not necessarily represent the views of the DOE

855 or the U.S. government. The U.S. government retains, and the publisher, by accepting the article for publication, acknowledges that the U.S. government retains a nonexclusive, paid-up, irrevocable, worldwide license to publish or reproduce the published form of this work, or allow others to do so, for U.S. government purposes.

\section{References}

Abdolali, A., Roland, A., van der Westhuysen, A., Meixner, J., Chawla, A., Hesser, T. J., Smith, J. M., and Sikiric, M. D.:

860 Large-scale hurricane modeling using domain decomposition parallelization and implicit scheme implemented in WAVEWATCH III wave model, Coastal Engineering, 157, 103656, doi: 10.1016/j.coastaleng.2020.103656, 2020 a.

Abdolali, A., Pringle, W. J., Roland, A., and Mehra, A.: Assessment of Global Wave Models on Unstructured Domains, AGU Fall Meeting IPoster Sessions, December 1-17, doi: 10.1002/essoar.10505107.1, 2020b.

Allaerts, D. and Meyers, J.: Boundary-layer development and gravity waves in conventionally neutral wind farms, J Fluid

865 Mech., 814:95-130, doi: 10.1017/jfm.2017.11, 2017.

Allaerts, D. and Meyers, J.: Gravity Waves and Wind-Farm Efficiency in Neutral and Stable Conditions, Bound.-Layer Meteorol., 166, 269-299, doi:10.1007/s10546-017-0307-5, 2018.

Allaerts, D., Quon, E., Draxl, C., and Churchfield, M. J.: Development of a time-height profile assimilation technique for large-eddy simulation, Boundary-Layer Meteorology, http://link.springer.com/article/10.1007/s10546-020-00538-5, 2020.

870 Andreas, E. L., Mahrt, L., and Vickers, D.: A new drag relation for aerodynamically rough flow over the ocean, J. Atmos. Sci., 69, 2520-2537, doi:10.1175/JAS-D-11-0312.1, 2012. 
https://doi.org/10.5194/wes-2021-156

Preprint. Discussion started: 21 February 2022

(c) Author(s) 2022. CC BY 4.0 License.

\section{(c) (1)}

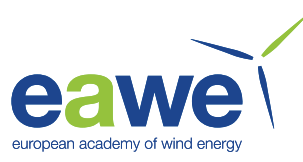

Angevine, W., Hare, J. E., Fairall, C. W., Wolfe, D. E., Hill, R. J., Brewer, W. A., and White, A. B.: Structure and formation of the highly stable marine boundary layer over the Gulf of Maine. J. Geophys. Res., 111, D23S22, doi:10.1029/2006JD007465, 2006.

Annoni, J., Bay, C., Johnson, K., Dall'Anese, E., Quon, E., Kemper, T., and Fleming, P.: A Framework for Autonomous Wind Farms: Wind Direction Consensus, Control and system identification, https://doi.org/10.5194/wes-2018-60, 2018. Anvari, M., Lohmann, G., Wächter, M., Milan, P., Lorenz, E., Heinemann, D., Tabar, M. R. R., and Peinke, J.: Short term fluctuations of wind and solar power systems, New J. Phys., 18, 063027, https://doi.org/10.1088/1367-2630/18/6/063027, 2016.

880 Archer, C. L., Colle, B. A., Veron, D. L., Veron, F., and Sienkiewicz, M. J.: On the predominance of unstable atmospheric conditions in the marine boundary layer offshore of the US northeastern coast, Journal of Geophysical Research: Atmospheres, 121, 8869- 8885, doi: 10.1002/2016JD024896, 2016.

Arya, S. P.: Introduction to Micrometeorology, 2nd ed., Academic Press, 2001.

ASTM: ASTM G73 - Standard Test Method for Liquid Impingement Erosion Using Rotating Apparatus, ASTM, 1-19, 8852012.

Bak, C., Forsting, A. M., and Sørensen, N. N.: The influence of leading edge roughness, rotor control and wind climate on the loss in energy production, Journal of Physics: Conference Series, 1618(5), [052050 ], doi: 10.1088/17426596/1618/5/052050, 2020.

Baldauf, M., Seifert, A., Forstner, J., Majewski, D., Raschendorfer, M., and Reinhardt, T.: Operational convective-scale numerical weather prediction with the COSMO Model: Description and sensitivities, Monthly Weather Review, 139, pp. 3887-3905, 2011.

Balluff, S., Bendfeld, J., and Krauter, S.: Short term wind and energy prediction for offshore wind farms using neural networks, 2015 International Conference on Renewable Energy Research and Applications (ICRERA), pp. 379-382, doi: 10.1109/ICRERA.2015.7418440, 2015.

895 Banta, R. M., Pichugina, Y. L., Brewer, W. A., James, E. P., Olson, J. B., Benjamin, S. G., Carley, J. R., Bianco, L., Djalalova, I. V., Wilczak, J. M., Hardesty, R. M., Cline, J., and Marquis, M. C.: Evaluating and Improving NWP Forecast Models for the Future: How the Needs of Offshore Wind Energy Can Point the Way, Bull. Amer. Meteor. Soc., 99, 11551176, doi: 10.1175/BAMS-D-16-0310.1, 2018.

Barthelmie, R. J., Dantuono, K. E., Renner, E. J., Letson, F. L., and Pryor, S. C.:Extreme Wind and Waves in U.S. East

900 Coast Offshore Wind Energy Lease Areas, Energies 2021, 14(4), 1053; doi: 10.3390/en14041053, 2021.

Bech, J. I., Hasager, C. B., and Ch Bak, C.: Extending the life of wind turbine blade leading edges by reducing the tip speed during extreme precipitation events, Wind Energ. Sci., 3, 729-748, doi: 10.5194/wes-3-729-2018, 2018.

Berg, L. K., Newsom, R. K., and Turner, D. D.: Year-Long Vertical Velocity Statistics Derived From Doppler Lidar in the Continental Convective Boundary Layer, Journal of Applied Meteorology and Climatology, 56, 9:2441-2454, PNNL-SA- 
https://doi.org/10.5194/wes-2021-156

Preprint. Discussion started: 21 February 2022

(c) Author(s) 2022. CC BY 4.0 License.

Bessac, J., Monahan, A. H., Christensen, H. M., and Weitzel, N.: Stochastic parameterization of subgrid-scale velocity enhancement of sea surface fluxes, Monthly Weather Review, 147(5), 1447-1469, doi: 10.1175/MWR-D-18-0384.1, 2019. Bianco, L., and Wilczak, J.: Convective Boundary-Layer Depth: Improved Measurement by Doppler Radar Wind Profile Using Fuzzy Logic Methods, J. Atmos. Oceanic Tech., 19, 1745-1758, 2002.

910 Bodini, N., Lundquist, J. K., and Kirincich, A.: Offshore wind turbines will encounter very low atmospheric turbulence, J. Phys: Conf. Ser., 1452, https://doi.org/10.1088/1742-6596/1452/1/012023, 2020.

Borvarán, D., Peña, A., and Gandoin, R.: Characterization of offshore vertical wind shear conditions in Southern New England, Wind Energy, doi: 10.1002/we.2583, accepted/in press.

Bossanyi, E.: Combining induction control and wake steering for wind farm energy and fatigue loads optimisation, J. Phys.:

915 Conf. Ser., 1037, 032011, https://doi.org/10.1088/1742-6596/1037/3/032011, 2018.

Bossuyt, J., Meneveau, C., and Meyers, J.: Wind farm power fluctuations and spatial sampling of turbulent boundary layers, J. Fluid Mech., 823, 329-344, https://doi.org/10.1017/jfm.2017.328, 2017.

Bright, R. J., Lian, X., and Pietrafesa, L. J.: Evidence of the Gulf Stream's influence on tropical cyclone intensity, Geophys. Res. Ltrs, 29, 1801-1804, doi: 10.1029/2002GL014920, 2002.

920 Brower, M.C.: Wind Resource Assessment: A Practical Guide to Developing a Wind Project, Wiley, 280 pp., 2012.

Browne, P.A., de Rosnay, P., Zuo, H., Bennett, A., and Dawson, A.: Weakly coupled ocean-atmosphere data assimilation in the ECMWF NWP system, Remote Sens., 11, 234, doi:10.3390/rs11030234, 2019.

Burk, S. D., and Thompson, W. T.: The summertime low-level jet and marine boundary layer structure along the California coast, Mon. Wea. Rev., 124, 668-686, 1996.

925 Businger, S., Graziano, T.M., Kaplan, M.L., and Rozumalski, R.A.: Cold-air cyclogenesis along the Gulf-Stream front: Investigation of diabatic impacts on cyclone development, frontal structure, and track, Meteor. Atmos. Phys., 88, 65-90, doi: 10.1007/s00703-003-0050-y, 2005.

Butterfield, S., Musial, W., Jonkman, J., and Sclavounos, P.: Engineering challenges for floating offshore wind turbines, Tech. rep., National Renewable Energy Laboratory (NREL), Golden, CO, 2007.

930 Chalikov, D.: The parameterization of the wave boundary layer, Journal of physical oceanography, 25(6), pp.1333-1349, 1995.

Chamorro, L. P., Lee, S.-J., Olsen, D., Milliren, C., Marr, J., Arndt, R. E. A., and Sotiropoulos, F.: Turbulence effects on a full-scale 2.5 MW horizontal-axis wind turbine under neutrally stratified conditions: Turbulence effects on a full-scale wind turbine, Wind Energ., 18, 339-349, https://doi.org/10.1002/we.1700, 2015.

935 Chamorro, L. P., and Porté-Agel, F.: A Wind-Tunnel Investigation of Wind-Turbine Wakes: Boundary-Layer Turbulence Effects, Boundary-Layer Meteorol, 132, 129-149, doi: 10.1007/s10546-009-9380-8, 2009.

Chamorro, L. P., and Porté-Agel, F.: Turbulent flow inside and above a wind farm: a wind-tunnel study, Energies 4(11), 1916-1936, 2011. 
https://doi.org/10.5194/wes-2021-156

Preprint. Discussion started: 21 February 2022

(c) Author(s) 2022. CC BY 4.0 License.

Chelton, D. B., Esbensen, S. K., Schlax, M. G., Thum, N., Freilich, M. H., Wentz, F. J., Gentemann, C. L., McPhaden, M. J., and Schopf, P. S.: Observations of coupling between surface wind stress and sea surface temperature in the eastern tropical Pacific, Journal of Climate, 14(7), pp.1479-1498, 2001.

Chen, S. S., Price, J. F., Zhao, W., Donelan, M. A., and Walsh, E. J.: The CBLAST-Hurricane program and the nextgeneration fully coupled atmosphere-wave-ocean models for hurricane research and prediction, Bull. Am. Meteorol. Soc., 88(3), 311-317, doi:10.1175/BAMS-88-3-311, 2007.

Christiansen, M. B., and Hasager, C. B.: Wake effects of large offshore wind farms identified from satellite SAR, Remote Sens. Environ., 98, 251-268, 2005.

Cifuentes-Lorenzen, A., Edson, J., and Zappa, C.: Air-Sea Interaction in the Southern Ocean: Exploring the Height of the Wave Boundary Layer at the Air-Sea Interface, Boundary-Layer Meteorology, 169. doi: 10.1007/s10546-018-0376-0, 2018.

Colle, B. A., Sienkiewicz, M. J., Archer, C., Veron, D., Veron, F., Kempton, W., and Mak, J. E.: Improving the Mapping and Prediction of Offshore Wind Resources (IMPOWR): Experimental Overview and First Results, Bulletin of the American Meteorological Society, 97, 1377-1390, doi: 10.1175/BAMS-D-14-00253.1, 2016.

Craig, A., Valcke, S., and Coquart, L.: Development and performance of a new version of the OASIS coupler, OASIS3MCT-3.0, Geoscientific Model Development, 10(9), 3297-3308. doi: 10.5194/gmd-10-3297-2017, 2017.

Crespo, A., and Hernández, J.: Turbulence characteristics in wind-turbine wakes, Journal of Wind Engineering and Industrial 955 Aerodynamics, 61, 71-85, doi: 10.1016/0167-6105(95)00033-X, 1996.

Dashtkar, A., Hadavinia, H., Sahinkaya, M. N., Williams, N. A., Vahid, S., Ismail, F., and Turner, M.: Rain erosion-resistant coatings for wind turbine blades: A review, Polymers and Polymer Composites, 27(8), pp. 443-475, 2019.

Debnath, M., Doubrawa, P., Optis, M., Hawbecker, P., and Bodini, N.: Extreme Wind Shear Events in US Offshore Wind Energy Areas and the Role of Induced Stratification, Wind Energy Science Discussions, 2050 (September), 1-22, 2020.

DeCosmo, J., Katsaros, K. B., Smith, S. D., Anderson, R. J., Oost, W. A., Bumke, K., and Chadwick, H.: Air-sea exchange of water vapor and sensible heat: The Humidity Exchange Over the Sea (HEXOS) results, Journal of Geophysical Research:

Oceans, 101(C5), 12 001- 12 016, 1996.

Deskos, G., del Carre, A., and Palacios, R.: Assessment of low-altitude atmospheric turbulence models for aircraft aeroelasticity, Journal of Fluids and Structures, 95, 102981, https://doi.org/10.1016/j.jfluidstructs.2020.102981, 2020.

965 Deskos, G., Lee, J. C. Y., Sprague, M. A., Draxl, C.: Review of wind-wave coupling models for large-eddy simulation of the marine atmospheric boundary layer, Journal of the Atmospheric Sciences, submitted 2021.

Dettling, S., Kosovic, B., Gagne, D. J., and Haupt, S. E.: Machine-Learning Model for Surface Layer Parameterization at the Air-Sea Interface, AMS Annual Meeting, Virtual, Jan. 12, 2021.

Di Giuseppe, F., Riccio, A., Caporaso, L., Bonafé, G., Gobbi, G. P., and Angelini, F.: Automatic detection of atmospheric 970 boundary layer height using ceilometer backscatter data assisted by a boundary layer model, Q. J. R. Meteorol. Soc., 138, 649-663, doi:10.1002/qj.964, 2012. 
https://doi.org/10.5194/wes-2021-156

Preprint. Discussion started: 21 February 2022

(c) Author(s) 2022. CC BY 4.0 License.

Dilip, D., and Porté-Agel, F.: Wind Turbine Wake Mitigation through Blade Pitch Offset, Energies, 10, 757, doi: 10.3390/en10060757, 2017.

Djalalova, I. V., Olson, J., Carley, J. R., Bianco, L., Wilczak, J. M., Pichugina, Y., Banta, R., Marquis, M., and Cline, J.: The POWER Experiment: impact of assimilation of a network of coastal wind profiling radars on simulating offshore winds in and above the wind turbine layer, Weather and Forecasting, pp.1071-1091, doi: 10.1175/WAF-D-15-0104.1, 2016. DOC/NOAA: NOAA Study to Inform Meteorological Observation for Offshore Wind Positioning of Offshore Wind Energy Resources (POWER), Department of Commerce/National Atmospheric and Oceanographic Administration, https://www.esrl.noaa.gov/gsd/renewable/AMR_DOE-FinalReport-POWERproject-1.pdf (accessed 4 Oct 2021), 2014. DOE: Workshop on Research Needs for Offshore Wind Resource Characterization: Summary Report. U.S. Department of Energy, doi: 10.2172/1572142, 2019.

Donelan, M. A.: Air-sea interaction, Ocean Engineering Science, 9B, 239-292, John Wiley and Sons, 1990.

Dörenkämper, M., Optis, M., Monahan, A., and Steinfeld, G.: On the offshore advection of boundary-layer structures and the influence on offshore wind conditions, Bound.-Layer Meteorol., 155(3), pp. 459-482, doi: 10.1007/s10546-015-0008-x, 9852015.

Dowell, D.C. and coauthors: The High-Resolution Rapid Refresh (HRRR): An hourly updating convection-allowing forecast model. Part 1: Motivation and system description. Wea. Forecasting, in review.

Draxl, C., Allaerts, D., Quon, E., and Churchfield, M.: Coupling mesoscale budget components to large-eddy simulations for wind energy applications, doi: 10.1007/s10546-020-00584-z, 2020.

990 Edson, J. B., and Fairall, C. W.: Similarity relationships in the marine atmospheric surface layer for terms in the TKE and scalar variance budgets, Journal of the atmospheric sciences, 55(13), pp.2311-2328, 1998.

Edson, J. B., Jampana, V., Weller, R. A., Bigorre, S. P., Plueddemann, A. J., Fairall, C. W., Miller, S. D., Mahrt, L., Vickers, D., \& Hersbach, H.: On the exchange of momentum over the open ocean, J. Phys. Oceanog., 43(8), 1589-1610, doi: 10.1175/JPO-D-12-0173.1, 2013.

995 Edson, J., Paluszkiewicz, T., Sandgathe, S., Vincent, L., Goodman, L., Curtin, T., Hollister, J., Colton, M., Anderson, S., Andreas, E., and Burk, S.: Coupled marine boundary layers and air-sea interaction initiative: combining process studies, simulations, and numerical models, Office of Naval Research, 1999.

Edson, J., Crawford, T., Crescenti, J., Farrar, T., Frew, N., Gerbi, G., Helmis, C., Hristov, T., Khelif, D., Jessup, A., and Jonsson, H.: The coupled boundary layers and air-sea transfer experiment in low winds. Bulletin of the American 1000 Meteorological Society, 88(3), pp.341-356, 2007.

Eisenberg, D., Laustsen, S., and Stege, J.: Wind turbine blade coating leading edge rain erosion model: Development and validation, Wind Energy, 1-10, doi: 10.1002/we.2200, 2018.

Emeis, S.: Wind energy meteorology: atmospheric physics for wind power generation, Springer, 2nd ed., 2018. 
https://doi.org/10.5194/wes-2021-156

Preprint. Discussion started: 21 February 2022

(c) Author(s) 2022. CC BY 4.0 License.

Fairall, C. W., Bradley, E. F., Hare, J. E., Grachev, A. A., and Edson, J. B.: Bulk Parameterization of Air-Sea Fluxes: Updates and Verification for the COARE Algorithm, Journal of Climate, 16(4), 571-591, doi:10.1175/15200442(2003)016〈0571:BPOASF) 2.0.CO;2, 2003.

Fairman, J. G., Schultz, D. M., Kirshbaum, D. J., Gray, S. L., and Barrett, A. I.: Climatology of size, shape, and intensity of precipitation features over Great Britain and Ireland, J. Hydrometeor., 18, 1595-1615, doi: 10.1175/JHM-D-16-0222.1, 2017.

1010 Field, P. R.,Cotton, R. J., McBeath, K., Lock, A. P., Webster, S., and Allan, R. P.:Improving a convection-permitting model simulation of a cold air outbreak, Quart. J. Roy. Meteor. Soc., 140, 124-138, doi: 10.1002/qj.2116, 2014.

Finger, A.: The role of the research platforms FINO 1-3 in the technical and ecological support research on offshore wind energy use. https://www.osti.gov/etdeweb/servlets/purl/21060112, 2007.

Fischer, P., Kerkemeier, S., Min, M., Lan, Y.-H., Phillips, M., Rathnayake, T., Merzari, E., Tomboulides, A., Karakus, A.,

1015 Chalmers, N., and Warburton, T.: NekRS, a GPU-Accelerated Spectral Element Navier-Stokes Solver, ArXiv. http://arxiv.org/abs/2104.05829, 2021.

Fleming, P., Annoni, J., Shah, J. J., Wang, L., Ananthan, S., Zhang, Z., Hutchings, K., Wang, P., Chen, W., and Chen, L.: Field test of wake steering at an offshore wind farm, Wind Energ. Sci., 2, 229-239, https://doi.org/10.5194/wes-2-229-2017, 2017.

1020 Fleming, P., King, J., Dykes, K., Simley, E., Roadman, J., Scholbrock, A., Murphy, P., Lundquist, J. K., Moriarty, P., Fleming, K., van Dam, J., Bay, C., Mudafort, R., Lopez, H., Skopek, J., Scott, M., Ryan, B., Guernsey, C., and Brake, D.: Initial results from a field campaign of wake steering applied at a commercial wind farm - Part 1, Wind Energ. Sci., 4, 273285, https://doi.org/10.5194/wes-4-273-2019, 2019.

Foreman, R. J., and Emeis, S.: Revisiting the Definition of the Drag Coefficient in the Marine Atmospheric Boundary Layer, 1025 Journal of Physical Oceanography, 40(10), 2325-2332, 2010.

Frandsen, S.T., Barthelmie, R. J., Rathmann, O., Jørgensen, H. E., Badger, J., Hansen, K., Ott, S., Rethore, P. E., Larsen, S. E., and Jensen, L. E.: Summary report: The shadow effect of large wind farms: measurements, data analysis and modeling, Risø National Laboratory/DTU, Risø-R-1615(EN): p. 34, 2007.

Friehe, C. A., Shaw, W. J., Rogers, D. P., Davidson, K. L., Large, W. G., Stage, S. A., Crescenti, G. H., Khalsa, S. J. S.,

1030 Greenhut, G. K. and Li, F.: Air-sea fluxes and surface layer turbulence around a sea surface temperature front, Journal of Geophysical Research: Oceans, 96(C5), pp.8593-8609, 1991.

Frolov, S., Bishop, C. H., Holt, T., Cummings, J., and Knuth, D.: Facilitating strongly coupled ocean-atmosphere data assimilation with an interface solver, Month. Wea. Rev., 144, 3-20, doi:10.1175/MWR-D-15-0041.1, 2016.

Fytanidis, D. K., Maulik, R., Balakrishnan, R., and Kotamarthi, R.: A physics-informed data-driven low order model for the 1035 wind velocity deficit at the wake of isolated buildings (Report \#ANL-21/24), Argonne National Laboratory, doi: 10.2172/1782670, 2021. 
https://doi.org/10.5194/wes-2021-156

Preprint. Discussion started: 21 February 2022

(c) Author(s) 2022. CC BY 4.0 License.

\section{(c) (1)}

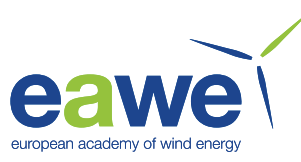

Gadde, S. N., and Stevens, R. J. A. M.: Interaction between low-level jets and wind farms in a stable atmospheric boundary layer, Phys. Rev. Fluids, 6, doi: 10.1103/PhysRevFluids.6.014603, 2021.

Gaertner, E., Rinker, J., Sethuraman, L., Zahle, F., Anderson, B., Barter, G., Abbas, N., Meng, F., Bortolotti, P., Skrzypiński, 1040 W. R., Scott, G., Feil, R., Bredmose, H., Dykes, K., Shields, M., Allen, C., and Viselli, A.: Definition of the IEA 15Megawatt Offshore Reference Wind Turbine, Golden, CO: National Renewable Energy Laboratory, NREL/TP-5000-75698, https://www.nrel.gov/docs/fy20osti/75698.pdf, 2020.

Gagne, D. J., McCandless, T. C., Kosovic, B., DeCastro, A., Loft, R. D., Haupt, S. E., and Yang, B.: January. Machine Learning Parameterization of the Surface Layer: Integration with WRF, In 100th American Meteorological Society Annual 1045 Meeting, AMS, 2020.

Garratt, J.R.: The internal boundary layer — A review. Boundary-Layer Meteorol 50, 171-203, doi: 10.1007/BF00120524, 1990.

Garratt, J. R.: The Atmospheric Boundary Layer, Cambridge University Press, 1994.

GE Renewable Energy: Haliade-X offshore wind turbine, https://www.ge.com/renewableenergy/wind-energy/offshore-

1050 wind/haliade-x-offshore-turbine, 2019.

Geernaert, G.: Bulk parameterizations for the wind stress and heat fluxes, Surface waves and fluxes, Springer, 91-172, 1990.

Geernaert, G. L., Katsaros, K. B., and Richter, K.: Variation of the drag coefficient and its dependence on sea state, Journal of Geophysical Research: Oceans, 91(C6), 7667-7679, 1986.

Geernaert, G. L., Larsen, S. E., and Hansen, F.: Measurements of the wind stress, heat flux, and turbulence intensity during 1055 storm conditions over the North Sea, Journal of Geophysical Research: Oceans, 92(C12), 13 127-13 139, 1987.

Gettelman, A., D.J. Gagne, C.-C. Chen, M.W. Christensen, Z.J. Lebo, H. Morrison, and G. Gantos: Machine learning the warm rain process. J. Adv. Modeling Earth Sys., 13, doi:10.1029/2020MS002268, 2021.

Gionfra, N., Sandou, G., Siguerdidjane, H., Faille, D., and Loevenbruck, P.: A distributed consensus control under disturbances for wind farm power maximization, in: 2017 IEEE 56th Annual Conference on Decision and Control (CDC),

10602017 IEEE 56th Annual Conference on Decision and Control (CDC), Melbourne, Australia, 2015-2020, https://doi.org/10.1109/CDC.2017.8263944, 2017.

Gottschall, J., Wolken-Möhlmann, G., Viergutz, T., and Lange, B.: Results and Conclusions of a Floating-lidar Offshore Test, Energy Procedia, 53, 156-161, doi: 10.1016/j.egypro.2014.07.224, 2014.

Grossman, R.L., and Betts, A. K.: Air-Sea Interaction during an Extreme Cold Air Outbreak from the Eastern Coast of the 1065 United States, Mon. Wea. Rev., 118(2): 324-342, 1990.

Gryning, S. E., Batchvarova, E., Brümmer, B., Jørgensen, H. and Larsen, S.: On the extension of the wind profile over homogeneous terrain beyond the surface boundary layer, Boundary-Layer Meteorology, 124(2), pp. 251-268, 2007. Gualtieri, G.: A comprehensive review on wind resource extrapolation models applied in wind energy, Renewable and Sustainable Energy Reviews, 102, pp. 215-233, 2019. 
https://doi.org/10.5194/wes-2021-156

Preprint. Discussion started: 21 February 2022

(c) Author(s) 2022. CC BY 4.0 License.

1070 Hanley, K. E., Belcher, S. E. and Sullivan, P. P.: A global climatology of wind-wave interaction, Journal of Physical Oceanography, 40(6), pp. 1263-1282, 2010.

, 2006.

Hao, X., Cao, T., Yang, Z., Li, T., and Shen, L.: Simulation-based study of wind-wave interaction, Procedia IUTAM, 26, 162-173, doi: 10.1016/j.piutam.2018.03.016, 2018.

1075 Hare, J. E., Hara, T., Edson, J. B., and Wilczak, J. M.: A similarity analysis of the structure of airflow over surface waves, Journal of physical oceanography, 27(6), pp. 1018-1037, 1997.

Hasager, C. B., Nygaard, N. G., Volker, P. J. H., Karagali, I., Andersen, S. J., and Badger, J.: Wind Farm Wake: The 2016 Horns Rev Photo Case Energies, 10(3), 317, doi:10.3390/en10030317, 2017.

Hasager, C. B., Vejen, F., Bech, J. I., Skrzypiński, W. R., Tilg, A.-M., and Nielsen, M.: Assessment of the rain and wind

1080 climate with focus on wind turbine blade leading edge erosion rate and expected lifetime in Danish Seas, Renewable Energy, 149, 91-102, doi: 10.1016/j.renene.2019.12.043, 2020.

Hasager, C. B., Vejen, F., Skrzypiński, W. R., and Tilg, A.-M.: Rain Erosion Load and Its Effect on Leading-Edge Lifetime and Potential of Erosion-Safe Mode at Wind Turbines in the North Sea and Baltic Sea, Energies 14(7):1959, doi: 10.3390/en14071959, 2021.

1085 Haupt, S. E., Kosovic, B., Shaw, W., Berg, L. K., Churchfield, M., Cline, J., Draxl, C., Ennis, B., Koo, E., Kotamarthi, R., Mazzaro, L., Mirocha, J., Moriarty, P., Muñoz-Esparza, D., Quon, E., Rai, R. K., Robinson, M., and Sever, G.: On Bridging a Modeling Scale Gap: Mesoscale to Microscale Coupling for Wind Energy, Bull. Amer. Meteorol. Soc., 100, doi: 10.1175/BAMS-D-18-0033.1, 2019.

Helmis, C. G., Wang, Q., Sgouros, G., Wang, S., and Halios, C.: Investigating the Summertime Low-Level Jet Over the East 1090 Coast of the U.S.A.: A Case Study, Boundary-Layer Meteorology, 149, 259-276, doi: 10.1007/s10546-013-9841-y, 2013. Herring, R., Dyer, K., Martin, F., and Ward, C.: The increasing importance of leading edge erosion and a review of existing protection solutions, Renewable and Sustainable Energy Reviews, 115, 109382, 2019.

Holtslag, M. C., Bierbooms, W. A. A. M., and van Bussel, G. J. W.: Extending the diabatic surface layer wind shear profile for offshore wind energy, Renewable Energy, 101, pp. 96-110, 2017.

1095 Hong, X., Martin, P. J., Wang, S., and Rowley, C.: High SST variability south of Martha’s Vineyard, J. Mar. Sys., 78(1), pp. 59-76, 2009.

Huffman, G. J., Bolvin, D. T., Braithwaite, D., Hsu, K., Joyce, R., and Xie, P.: NASA Global Precipitation Measurement Integrated Multi-satellitE Retrievals for GPM (IMERG), Algorithm Theoretical Basis Doc., version 4.4, 30 pp. https://pps.gsfc.nasa.gov/Documents/IMERG_ATBD_V4.pdf, 2014.

1100 Husain, N. T., Hara, T., Buckley, M. P., Yousefi, K., Veron, F., and Sullivan, P. P.: Boundary Layer Turbulence over Surface Waves in a Strongly Forced Condition: LES and Observation, J. Phys. Oceanogr., 49, 1997-2015, doi: 10.1175/JPOD-19-0070, 2019. 
https://doi.org/10.5194/wes-2021-156

Preprint. Discussion started: 21 February 2022

(c) Author(s) 2022. CC BY 4.0 License.

Igel, A. L., van den Heever, S., and Johnson, J. S.: Meteorological and Land Surface Properties Impacting Sea Breeze Extent and Aerosol Distribution in a Dry Environment, J. Geophys. Res., doi: 10.1002/2017JD027339, 2017.

1105 International Electrotechnical Commission: IEC 61400-1:2019-02 (Fourth Edition): Wind energy generation systems - Part 1: Design Requirements, IEC 61400-1:2019-02, available at: https://standards.iteh.ai/catalog/standards/iec/3454e370-7ef2468e-a074-7a5c1c6cb693/iec-61400-1-2019 (last access: 15 July 2020), 2019.

IRENA: Future of Wind: Deployment, investment, technology, grid integration and socio-economic aspects, International Renewable Energy Agency, Retrieved from www.irena.org/publications, 2019.

1110 Jacob, R., Larson, J., and Ong, E.: M × N communication and parallel interpolation in community climate system model version 3 using the model coupling toolkit, Int. J. High Perform. Comput. Appl., 19(3), 293-307, doi:10.1177/1094342005056116, 2005.

Jacox, M., Alexander, M. A., and Stock, C. A.: On the skill of seasonal sea surface temperature forecasts in the California Current System and its connection to ENSO variability, Clim. Dyn., 53, 7519-7533, doi: 10.1007/s00382-017-3608-y, 2019.

1115 Janssen, P. A. E. M.: The interaction of ocean waves and wind, University Press, Cambridge, UK, 2004.

James, E.P. and coauthors: The High-Resolution Rapid Refresh (HRRR): An hourly updating convection-allowing forecast model. Part 2: Forecast performance. Wea. Forecasting, in review.

Jiang, G. Q., Xu, J., and Wei, J.: A Deep Learning Algorithm of Neural Network for the Parameterization of Typhoon-Ocean Feedback in Typhoon Forecast Models, Geophysical Research Letters, 45(8), 3706-3716, doi: 10.1002/2018GL077004,

11202018.

Jiang, H., and Edson, J. B.: Characterizing marine atmospheric boundary layer to support offshore wind energy research, Journal of Physics: Conference Series, 1452(1), 2020.

Jiménez, P. A., and Dudhia, J.: On the Need to Modify the Sea Surface Roughness Formulation over Shallow Waters. Journal of Applied Meteorology and Climatology,57(5), 1101-1110, 2018.

1125 Kalverla, P. C., Steeneveld, G.-J., Ronda, R. J., Holtslag, A. A. M.: An observational climatology of anomalous wind events at offshore meteomast IJmuiden (North Sea), J. Wind Eng. and Ind. Aerodyn., 165, pp. 86-89, doi:

10.1016/j.jweia.2017.03.008, 2017.

Kalvig, S., Gudmestad, O. T., and Winther, N.: Exploring the gap between 'best knowledge' and 'best practice' in boundary layer meteorology for offshore wind energy, Wind Energy, 17, 161-171, doi:10.1002/we.1572, 2014.

1130 Kapoor, A., Ouakka, S., Arwade, S. R., Lundquist, J. K., Lackner, M. A., Myers, A. T., Worsnop, R. P., and Bryan, G. H.: Hurricane eyewall winds and structural response of wind turbines, Wind Energ. Sci., 5, 89-104, doi: 10.5194/wes-5-89$2020,2020$.

Kathiravelu, G., Lucke, T., and Nichols, P.: Rain Drop Measurement Techniques: A Review, Water-SUI, 8(1), 29, doi:10.3390/w8010029, 2016.

1135 Keegan, M. H., Nash, D. H., and Stack, M. M.: On erosion issues associated with the leading edge of wind turbine blades, Journal of Physics D: Applied Physics, 46(38), p.383001, 2013. 
https://doi.org/10.5194/wes-2021-156

Preprint. Discussion started: 21 February 2022

(c) Author(s) 2022. CC BY 4.0 License.

Kelley, N.D.: Turbulence-Turbine Interaction: The Basis for the Development of the TurbSim Stochastic Simulator, NREL Tech. Rpt NREL/TP-5000-52353, 2011.

Kelley, N. D., Jonkman, B. J., and Scott, G. N., The Great Plains turbulence environment: its origins,

1140 impact and simulation, National Renewable Energy Laboratory Conference, Paper No. NREL/CP-500-40176, 2006.

Khairoutdinov, M., Randall, D., and DeMott, C.: Simulations of the Atmospheric General Circulation Using a Cloud-

Resolving Model as a Superparameterization of Physical Processes, J. Atmos. Sci., 62, 2136-2154, doi: 10.1175/JAS3453.1, 2005.

Khain, A. P., Beheng, K. D., Heymsfield, A., Korolev, A., Krichak, S. O., Levin, Z., Pinsky, M., Phillips, V., Prabhakaran,

1145 T., Teller, A., van den Heever, A. C., and Yano, J.-I.: Representation of microphysical processes in cloud-resolving models: Spectral (bin) microphysics versus bulk parameterization, Reviews of Geophysics, 53(2), pp. 247-322, doi: 10.1002/2014RG000468, 2015.

Khain, A. P., and Lynn, B.: Simulation of a super cell storm in clean and dirty atmosphere, Journal of Geophysical Research, 114, D19209, doi:10.1029/2009JD011827, 2009.

1150 Kim, E., Manuel, L., Curcic, M., Chen, S. S., Phillips, C., and Veers, P.: On the use of coupled wind, wave, and current fields in the simulation of loads on bottom-supported offshore wind turbines during hurricanes: March 2012 - September 2015, Tech. rep., United States, 2016.

Kirincich, A.: A metocean reference station for offshore wind energy research in the U.S., J. Phys.: Conf. Ser., 1452, doi: 10.1088/1742-6596/1452/1/012028, 2020.

1155 Lagerquist, R., Turner, D. D., Ebert-Uphoff, I., Stewart, J., and Hagerty, V.: Using deep learning to emulate and accelerate a radiative transfer model, J. Atmos. Oceanic Technol, 38, 1673-1696, doi:10.1175/JTECH-D-21-0007.1, 2021.

Lambaerts, J., Lapeyre, G., Plougonven, R., and Klein, P.: Atmospheric response to sea surface temperature mesoscale structures, Journal of Geophysical Research: Atmospheres, 118, 9611-9621, doi: 10.1002/jgrd.50769, 2013.

Larson, J., Jacob, R., and Ong, E.: The model coupling toolkit: A new Fortran90 toolkit for building multiphysics parallel

1160 coupled models, Int. J. High Perform. Comput. Appl., 19(3), 277-292, doi:10.1177/1094342005056115, 2005.

Lee, S., Churchfield, M. J., Moriarty, P. J., Jonkman, J., and Michalakes, J.: A Numerical Study of Atmospheric and Wake Turbulence Impacts on Wind Turbine Fatigue Loadings, 135, 031001, https://doi.org/10.1115/1.4023319, 2013.

Letson, F. W., Barthelmie, R. J., and Pryor, S. C.: RADAR- derived precipitation climatology for wind turbine blade leading edge erosion, Wind Energy Sci,. 5, 331-347, 2020a.

1165 Letson, F., Shepherd, T. J., Barthelmie, R. J., and Pryor, S. C.: Modelling Hail and Convective storms with WRF for Wind Energy Applications, J. Phys.: Conf. Ser., 1452 012051, 2020 b.

Li, G., Curcic, M., Iskandarani, M., Chen, S. S., and Knio, O. M.: Uncertainty propagation in coupled atmosphere-waveocean prediction system: A study of Hurricane Earl (2010), Mon. Weather Rev., 147(1), 221-245, doi:10.1175/MWR-D-170371.1, 2019. 
https://doi.org/10.5194/wes-2021-156

Preprint. Discussion started: 21 February 2022

(c) Author(s) 2022. CC BY 4.0 License.

1170 Li, X., Tao, W.-K., Khain, A. P., Simpson, J., and Johnson, D. E.: Sensitivity of a cloud-resolving model to bulk and explicit bin microphysical schemes. Part I: Validation with a PRE-STORM case, J. Atmos. Sci., 66, 3-21, doi:10.1175/2008JAS2646.1, 2009a.

Li, X., Tao, W.-K., Khain, A. P., Simpson, J., and Johnson, D. E.: Sensitivity of a cloud-resolving model to bulk and explicit bin microphysical schemes. Part II: Cloud microphysics and storm dynamics interactions, J. Atmos. Sci., 66, 22-40. 2009 b.

1175 Lin, Z., Liu, X., and Collu, M.: Wind power prediction based on high-frequency SCADA data along with isolation forest and deep learning neural networks, International Journal of Electrical Power \& Energy Systems, 118, doi:

10.1016/j.ijepes.2020.105835, 2020.

Liu, B., Liu, H., Xie, L., Guan, C., and Zhao, D.: A Coupled atmosphere-wave-ocean modeling system: simulation of the intensity of an idealized tropical cyclone, Mon. Weather Rev., 139(1), 132-152, doi:10.1175/2010MWR3396.1, 2011.

1180 Loftus, A. M., and Cotton, W. R.: Examination of CCN impacts on hail in a simulated supercell storm with triple-moment hail bulk microphysics, Atmos. Res., 147-148, 183-204, 2014.

Lukassen, L. J., Stevens, R. J. A. M., Meneveau, C., and Wilczek, M.: Modeling space-time correlations of velocity fluctuations in wind farms, Wind Energy, 21, 474-487, https://doi.org/10.1002/we.2172, 2018.

Lundquist, J. K., DuVivier, K. K., Kaffine, D., and Tomaszewski, J. M.: Costs and consequences of wind turbine wake

1185 effects arising from uncoordinated wind energy development, Nature Energy, doi: 10.1038/s41560-018-0281-2, 2018.

Luo, T., Yuan, R., and Wang, Z.: Lidar-based remote sensing of atmospheric boundary layer height over land and ocean, Atmospheric Measurement Techniques, 7(1), pp. 173-182, 2014.

Magnusson, M., and Smedman, A.-S.: Influence of Atmospheric Stability on Wind Turbine Wakes, 18, 139-152, 1994.

Mahrt, L.: Stratified atmospheric boundary layers, Bound.-Layer Meteor, 90, 375-396, 1999.

1190 Mahrt, L., Vickers, D., Edson, J., Wilczak, J. M., Hare, J., and Hojstrup, J.: Vertical Structure of Turbulence In Offshore Flow During Rasex, Boundary-Layer Meteorology, 100(1), 47-61, 2001.

Mahrt, L., Vickers, D., and Andreas, E. L.: Low-level wind maxima and structure of the stably stratified boundary layer in the coastal zone, J. Appl. Meteorol. Climat., 53(2), 363-376, 2014.

McCandless, T. C., Gagne, D. J., Kosovic, B., Haupt, S. E., Yang, B., Becker, C., and Schreck, J.: Machine Learning for

1195 Improving Surface Layer Flux Estimates, submitted to Boundary Layer Meteorology, in revision, 2021.

Milbrandt, J. A., and Yau, M. K.: A multimoment bulk microphysics parameterization. Part III: Control simulation of a hailstorm, Journal of the Atmospheric Sciences, 63, pp. 3114-3136, 2006.

Miller, S. C., Friehe, C., Hristov, T., Edson, J. and Wetzel, S.: Wind and turbulent profiles in the surface layer over ocean waves, Wind-Over-Wave Couplings, ed. Sajjadi, S. G., Thomas, N. H. and Hunt, J. C. R., Oxford University Press, 91-98, 12001999.

Minda, L., and Chandrasekar, V.: An algorithm for drop-size distribution retrieval from GPM dual-frequency precipitation radar, IEEE Transactions on Geoscience and Remote Sensing, 52(11), pp. 6813630, 2014. 
https://doi.org/10.5194/wes-2021-156

Preprint. Discussion started: 21 February 2022

(c) Author(s) 2022. CC BY 4.0 License.

Mishnaevsky Jr., L.: Repair of wind turbine blades: Review of methods and related computational mechanics problems, Renewable Energy, 140, pp. 828-839, 2019.

1205 Monin, A. S., and Obukhov, A.M.: Basic laws of turbulent mixing in the surface layer of the atmosphere. Contrib. Geophys. Inst. Acad. Sci. USSR, 151(163), p.e187, 1954.

Mora, E. B., Spelling, J., van der Weijde, A. H., and Pavageau, E.-M.: The effects of mean wind speed uncertainty on project finance debt sizing for offshore wind farms, Applied Energy, 252, 113419, https://doi.org/10.1016/j.apenergy.2019.113419, 2019.

1210 Morrison, H., Thompson, G., and Tatarskii, V.: Impact of cloud microphysics on the development of trailing stratiform precipitation in a simulated squall line: Comparison of one- and two-moment schemes, Monthly Weather Review, 137, pp. 991-1007, 2009.

Morrison, H., van Lier-Walqui, M., Fridlind, A. M., Grabowski, W. W., Harrington, J. Y., Hoose, C., Korolev, A., Kumjian, M. R., Millbrandt, J. A., Pawlowska, H., Posselt, D. J., Prat, O. P., Reimel, K. J., Shima, S.-I., van Diedenhoven, B., Xue, L.:

1215 Confronting the challenge of modeling cloud and precipitation microphysics, JAMES, doi: 10.1029/2019MS001689, 2020.

Munters, W. and Meyers, J.: Dynamic Strategies for Yaw and Induction Control of Wind Farms Based on Large-Eddy Simulation and Optimization, Energies, 11, 177, https://doi.org/10.3390/en11010177, 2018.

Murphy, P., Lundquist, J. K., and Fleming, P.: How wind speed shear and directional veer affect the power production of a megawatt-scale operational wind turbine, Wind Energ. Sci. Discuss., doi: 10.5194/wes-2019-86, 2020.

Musial, W., Beiter, P., Spitsen, P., Nunemaker, J., and Gevorgian, V.: 2018 Offshore Wind Technologies Market Report. (Technical Report), Washington, D.C.: U.S. Department of Energy Office of Energy Efficiency \& Renewable Energy. https://www.energy.gov/sites/prod/files/2019/09/f66/2018\%20Offshore\%20Wind\%20Technologies\%20Market\%20Report.p df. 2019.

Norin, L.: A quantitative analysis of the impact of wind turbines on operational Doppler weather radar data. Atmos. Meas.

1225 Tech., 8, 593-609, doi:10.5194/amt-8-593-2015, 2015.

Nygaard, N. G.: Wakes in very large wind farms and the effect of neighbouring wind farms, J. Phys.: Conf. Ser., 524, doi: 10.1088/1742-6596/524/1/012162, 2014.

Obukhov, A. M.: Turbulence in an atmosphere with non-uniform temperature. Tr. Inst. Teor. Geofiz. Akad. Nauk. SSSR, 1, pp. $95-115,1946$

1230 Olson, J. B., Kenyon, J. S., Djalalova, I., Bianco, L., Turner, D. D., Pichugina, Y., Choukulkar, A., Toy, M. D., Brown, J. M., Angevine, W. M., and Akish, E.: Improving wind energy forecasting through numerical weather prediction model development, Bull. Amer. Meteor. Soc., 100, 2201-2220, doi: 10.1175/BAMS-D-18-0040.1, 2019.

Oost, W. A., Komen, G. J., Jacobs, C. M. J., and Van Oort, C.: New evidence for a relation between wind stress and wave age from measurements during asgamage, Boundary-Layer Meteorology, 103(3), 409-438, 2002.

1235 Palm, S. P., Selmer, P., Yorks, J., Nicholls, S., and Nowottnick, E.: Planetary boundary layer height estimates from ICESat-2 and CATS backscatter measurements, Front. Remote Sens., 13, doi: 10.3389/frsen.2021.716951, 2021. 
https://doi.org/10.5194/wes-2021-156

Preprint. Discussion started: 21 February 2022

(c) Author(s) 2022. CC BY 4.0 License.

\section{(c) (1)}

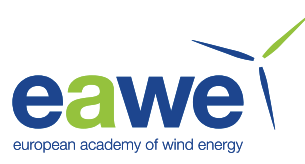

Patton, E. G., Sullivan, P. P., Kosović, B., Dudhia, J., Mahrt, L., Žagar, M., and Marić, T.: On the influence of swell propagation angle on surface drag, J. Appl. Meteorol. Climatol., 58(5), 1039-1059, doi:10.1175/JAMC-D-18-0211.1, 2019. Peña, A., Gryning, S.E. and Hasager, C.B.: Measurements and modelling of the wind speed profile in the marine atmospheric boundary layer, Boundary-layer meteorology, 129(3), pp.479-495, 2008.

Peña, A., Gryning, S.E. and Hasager, C.B.: Comparing mixing-length models of the diabatic wind profile over homogeneous terrain. Theoretical and Applied Climatology, 100(3-4), pp.325-335, 2010.

Piazza, M., Terray, L., Boé, J., Maisonnave, E., and Sanchez-Gomez, E.: Influence of small-scale North Atlantic sea surface temperature patterns on the marine boundary layer and free troposphere: A study using the atmospheric ARPEGE model,

1245 Climate dynamics, 46(5-6), pp.1699-1717, 2016.

Pichugina, Y. L., Banta, R. M., Brewer, W. A., Sandberg, S. P., \& Hardesty, R. M. (2012). Doppler Lidar-Based Wind-

Profile Measurement System for Offshore Wind-Energy and Other Marine Boundary Layer Applications, Journal of Applied Meteorology and Climatology, 51(2), pp. 327-349, doi: 10.1175/JAMC-D-11-040.1, 2012.

Pichugina, Y. L., Brewer, W. A., Banta, R. M., Choukulkar, A., Clack, C. T. M., Marquis, M. C., McCarty, B. J.,

1250 Weickmann, A. M., Sandberg, S. P., Marchbanks, R. D., Hardesty, R. M.: Properties of the offshore low level jet and rotor layer wind shear as measured by scanning Doppler lidar, Wind Energy, 20(6), pp. 987-1002, doi: 10.1002/we.2075, 2017. Platis, A., Siedersleben, S. K., Bange, J., Lampert, A., Bärfuss, K., Hankers, R., Cañadillas, B., Foreman, R., SchulzStellenfleth, J., Djath, B., Neumann, T., and Emeis, S.: First in situ evidence of wakes in the far field behind offshore wind farms, Scientific Reports, 8(1), 2163, 2018.

1255 Porté-Agel, F., Bastankhah, M., and Shamsoddin, S.: Wind-Turbine and Wind-Farm Flows: A Review, Boundary-Layer Meteorol, 174, 1-59, https://doi.org/10.1007/s10546-019-00473-0, 2020.

Pringle, W. J., and Kotamarthi, V. R.: Coupled Ocean Wave-Atmosphere Models for Offshore Wind Energy, Tech. Report \#ANL/EVS-21/8. Argonne National Laboratory, Lemont, IL, https://www.researchgate.net/publication/353029144, 2021. Pryor, S. C., Shepherd, T. J., Volker, P. J. H., Hahmann, A. N., and Barthelmie, R. J.: “Wind Theft” from Onshore Wind 1260 Turbine Arrays: Sensitivity to Wind Farm Parameterization and Resolution, J. Appl. Meteor. Climatol., 59, 153-174, doi: 10.1175/JAMC-D-19-0235.1, 2020.

Ramirez, L., Fraile, D., and Brindley, G.: Offshore wind in Europe: Key trends and statistics 2019, https://windeurope.org/wp-content/uploads/files/about-wind/statistics/WindEurope-Annual-Offshore-Statistics-2019.pdf (last accessed 5 November 2020), 2020.

1265 Richter, D. H., and Sullivan, P. P.: Sea surface drag and the role of spray, Geophysical Research Letters, 40, 656-660, doi: 10.1002/grl.50163, 2013.

Rios Gaona, M. F., Overeem, A., Leijnse, H., and Uijlenhoet, R.: First-Year Evaluation of GPM Rainfall over the Netherlands: IMERG Day 1 Final Run (V03D), Journal of Hydrometeorology, 17, 11, doi: 10.1175/JHM-D-16-0087.1, 2016. 
https://doi.org/10.5194/wes-2021-156

Preprint. Discussion started: 21 February 2022

(c) Author(s) 2022. CC BY 4.0 License.

1270 Rutgersson A., Smedman, A.-S., and Högström, U.: Use of conventional stability parameters during swell, Journal of Geophysical Research, 106: 27, 117-27, 134, doi: 10.1029/2000JC000543, 2001.

Sanderse, B., van der Pijl, S.P., and Koren, B.: Review of computational fluid dynamics for wind turbine wake aerodynamics, Wind Energy, 14, 799-819, doi:10.1002/we.458, 2011.

Sathe, A., Gryning, S.E., and Peña, A.: Comparison of the atmospheric stability and wind profiles at two wind farm sites over a long marine fetch in the North Sea, Wind Energy, 14(6), pp.767-780, 2011.

Sauer, J., and Muñoz-Esparza, D.: The FastEddy ${ }^{\circledR}$ Resident-GPU Accelerated Large-Eddy Simulation Framework: Model Formulation, Dynamical-Core Validation and Performance Benchmarks, Journal of Advances in Modeling Earth Systems, 12, e2020MS002100, doi: 10.1029/2020MS002100, 2020.

Savelyev, S. and Taylor, P.A.: Internal boundary-layers I - modified height formulae in neutral and diabatic conditions;

1280 Boundary-Layer Meteorology, 115, pp. 1-25, doi: 10.1007/s10546-004-2122-z, 2005.

Schaller, E.: Time and height variability of the sensible heat flux in the surface layer, Boundary-Layer Meteorology, 11(3), pp.329-354, 1977.

Sebastian, T., and Lackner, M. A.: Development of a free vortex wake method code for offshore floating wind turbines, Renewable Energy, 46, 269-275, doi:10.1016/j.renene.2012.03.033, 2012.

1285 Seifert, J. K., Kraft, M., Kühn, M., and Lukassen, L. J.: Correlations of power output fluctuations in an offshore wind farm using high-resolution SCADA data, Wind Energ. Sci., 6, 997-1014, https://doi.org/10.5194/wes-6-997-2021, 2021.

Semedo, A., Saetra, Ø., Rutgersson, A., Kahma, K. K., and Pettersson, H.: Wave-induced wind in the marine boundary layer, Journal of the Atmospheric Sciences, 66, pp. 2256-2271, 2009.

Semedo, A., Sušelj, K., Rutgersson, A., and Sterl, A.: A global view on the wind sea and swell climate and variability from 1290 ERA-40, Journal of Climate, 24(5), pp.1461-1479, 2011.

Seroka, G., Fredj, E., Kohut, J., Dunk, R., Miles, T., and Glenn, S.: Sea breeze sensitivity to coastal upwelling and synoptic flow using Lagrangian methods, Journal of Geophysical Research: Atmospheres, 123(17), pp.9443-9461, 2018.

Scher, S.: Toward data-driven weather and climate forecasting: Approximating a simple general circulation model with deep learning, Geophys. Res. Lett., 45, 12616-12622, 2018.

1295 Schneemann, J., Theuer, F., Rott, A., Dörenkämper, M., and Kühn, M.: Offshore wind farm global blockage measured with scanning lidar, Wind Energ. Sci., 6, 521-538, https://doi.org/10.5194/wes-6-521-2021, 2021.

Shaw, W. J., Berg, L. K., Cline, J., Draxl, C., Djalalova, I., Grimit, E. P., Lundquist, J. K., Marquis, M., McCaa, J., Olson, J. B., Sivaraman, C., Sharp, J., and Wilczak, J. M.: The Second Wind Forecast Improvement Project (WFIP2): general overview, Bull. Amer. Meteorol. Soc., 100, 1687-1699, doi: 10.1175/BAMS-D-18-0036.1, 2019.

1300 Shaw, W. J., Draher, J., Garcia Medina, G., Gorton, A. M., Krishnamurthy, R., Newsom, R. K., Pekour, M. S., Sheridan, L. M., and Yang, Z.: General Analysis of Data Collected from DOE Lidar Buoy Deployments Off Virginia and New Jersey, PNNL-29823, Richland, WA: Pacific Northwest National Laboratory, doi: 10.2172/1632348, 2020. 
https://doi.org/10.5194/wes-2021-156

Preprint. Discussion started: 21 February 2022

(c) Author(s) 2022. CC BY 4.0 License.

Shimada, S., Ohsawa, T., Kogaki, T., Steinfeld, G., and Heinemann, D.: Effects of sea surface temperature accuracy on offshore wind resource assessment using a mesoscale model, Wind Energy, 18(10), 1839-1854, 2015.

1305 Shutt, M., and Seim, H.: Assessment of Stability-Based Characterizations of North Carolina's Offshore Wind Resource Using a Nested Boundary Layer Method, J. of Energy and Power Tech., 2, doi:10.21926/jept.2002006, 2020.

Siedersleben, S. K., Lundquist, J. K., Platis, A., Lampert, A., Bärfuss, K., Cañadillas, B., Djath, B., Schulz-Stellenfleth, J., Neumann, T., Bange, J., Emeis, S.: Micrometeorological impacts of offshore wind farms as seen in observations and simulations, Environ. Res. Lett. 13(12), doi: 10.1088/1748-9326/aaea0b, 2018.

1310 Siedersleben, S. K., Platis, A., Lundquist, J. K., Djath, B., Lampert, A., Bärfuss, K., Cañadillas, B., Schulz-Stellenfleth, J., Bange, J., Neumann, T., and Emeis, S.: Turbulent kinetic energy over large offshore wind farms observed and simulated by the mesoscale model WRF (3.8.1), Geosci. Model Dev., 13, pp. 249-268, doi: 10.5194/gmd-13-249-2020, 2020.

Sjöblom, A., and Smedman, A. S.: Vertical structure in the marine atmospheric boundary layer and its implication for the inertial dissipation method, Boundary-layer meteorology, 109(1), pp.1-25, 2003.

1315 Skamarock, W. C., Klemp, J. B., Dudhia, J., Gill, D. O., Barker, D., Duda, M. G., Huang, X.-Y.,Wang, W., and Powers, J. G.: A description of the advanced research WRF version 3, Report No. NCAR/TN-4751STR, National Center for Atmospheric Research, Boulder, CO, 2008.

Skrzypiński, W. R., Bech, J. I., Hasager, C. B., Tilg, A.-M., and Ch Bak, F. V.: Optimization of the erosion-safe operation of the IEA Wind 15 MW Reference Wind Turbine, J. Phys.: Conf. Ser., 1618, 052034, doi:10.1088/1742-6596/1618/5/052034, 2020.

Skyllingstad, E. D., Vickers, D., Mahrt, L., and Samelson, R.: Effects of mesoscale sea-surface temperature fronts on the marine atmospheric boundary layer, Boundary-layer meteorology, 123(2), pp .219-237, 2007.

Small, R. D., deSzoeke, S. P., Xie, S. P., O’Neill, L., Seo, H., Song, Q., Cornillon, P., Spall, M., and Minobe, S.: Air-sea interaction over ocean fronts and eddies, Dynamics of Atmospheres and Oceans, 45(3-4), pp. 274-319, doi: 10.1016/j.dynatmoce.2008.01.001, 2008.

Slot, H. M., Gelinck, E. R. M., Rentrop, C., Van der Heide, E.: Leading edge erosion of coated wind turbine blades: review of coating life models, Renew. Energy, 80, pp. 387-848, doi: 10.1016/j.renene.2015.02.036, 2015.

Smedman, A., Högström, U., Sahlee, E., Drennan, W. M., Kahma, K. K., Pettersson, H., and Zhang, F.: Observational study of marine atmospheric boundary layer characteristics during swell, J. Atmos. Sci., 66, 2747-2763, doi:10.1175/2009JAS2952.1, 2009.

Smith, S. D., Anderson, R. J., Oost, W. A., Kraan, C., Maat, N., De Cosmo, J., Katsaros, K. B., Davidson, K. L., Bumke, K., Hasse, L., and Chadwick, H. M.: Sea surface wind stress and drag coefficients: The hexos results, Boundary-Layer Meteorology, 60 (1), 109-142, 1992.

Spall, M.A.: Midlatitude wind stress-sea surface temperature coupling in the vicinity of oceanic fronts, Journal of Climate, 1335 20(15), pp.3785-3801, 2007. 
https://doi.org/10.5194/wes-2021-156

Preprint. Discussion started: 21 February 2022

(c) Author(s) 2022. CC BY 4.0 License.

\section{(c) (1)}

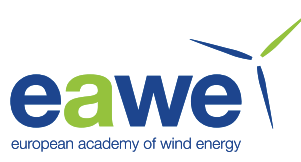

Sprague, M., Ananthan, S., Vijayakumar, G., and Robinson, M.: ExaWind: A multifidelity modeling and simulation environment for wind energy, J. Phys., 1452, 012071, doi: 10.1088/1742-6596/1452/1/012071, 2020.

Steinbuch, M., de Boer, W. W., Bosgra, O. H., Peters, S. A. W. M., and Ploeg, J.: Optimal control of wind power plants, Journal of Wind Engineering and Industrial Aerodynamics, 27, 237-246, https://doi.org/10.1016/0167-6105(88)90039-6, 13401988.

Stevens, R., Taylor V., Nichols, J., Maccabe, A. B., Yelick, K., and Brown, D.: Report on the Department of Energy (DOE) Town Halls on Artificial Intelligence (AI) for Science, U.S. DOE Office of Science, https://www.anl.gov/ai-for-sciencereport, 2020.

Strobach, E., Sparling, L. C., Rabenhorst, S. D., and Demoz, B.: Impact of Inland Terrain on Mid-Atlantic Offshore Wind 1345 and Implications for Wind Resource Assessment: A Case Study, Journal of Applied Meteorology and Climatology, 57, 777796, doi: 10.1175/JAMC-D-17-0143.1, 2018.

Stull, R. B.: An Introduction to Boundary Layer Meteorology, Dordrecht, The Netherlands: Kluwer Academic Publishers, ISBN 9027727686, 1988.

Sullivan, P. P., Banner, M. L., Morison, R. P., and Peirson, W. L.: Impacts of wave age on turbulent flow and drag of steep waves, Procedia IUTAM, 26, 174-183, 2018a.

Sullivan, P. P., Banner, M. L., Morison, R. P., and Peirson, W. L.: Turbulent flow over steep steady and unsteady waves under strong wind forcing, Journal of Physical Oceanography, 48(1), 3-27, doi:10.1175/JPO-D-17-0118.1, 2018b.

Sullivan, P. P., Edson, J. B., Hristov, T., and McWilliams, J. C.: Large-eddy simulations and observations of atmospheric ma rine boundary layers above nonequilibrium surface waves, Journal of the Atmospheric Sciences, 65(4), 1225-1245, 2008.

1355 Sullivan, P. P., and McWilliams, J. C.: Dynamics of Winds and Currents Coupled to Surface Waves, Annu. Rev. Fluid Mech., 42, 19-42, doi:10.1146/annurev-fluid-121108-14554, 2010.

Sullivan, P. P., McWilliams, J. C., and Patton, E. G.: Large-eddy simulation of marine atmospheric boundary layers above a spectrum of moving waves, J. Atmos. Sci., 71(11), 4001-4027, doi:10.1175/JAS-D-14-0095.1, 2014.

SWAN Team: SWAN: Scientific and technical documentation (SWAN Cycle III version 41.31A), Delft, The Netherlands: Delft University of Technology, http://swanmodel.sourceforge.net/download/zip/swantech.pdf, 2020.

Tang, Q., Mu, L., Sidorenko, D., Goessling, H., Semmle, T., and Nerger, L.: Improving the ocean and atmosphere in a coupled ocean-atmosphere model by assimilating satellite sea-surface temperature and subsurface profile data, Q. J. Roy. Meteor. Soc., 146, 4014-4029, doi: 10.1002/qj.3885, 2020.

Taylor, P. K., and Yelland, M. J.: The Dependence of Sea Surface Roughness on the Height and Steepness of the Waves, 1365 Journal of Physical Oceanography, 31(2), 572-590, 2001.

Tilg, A.-M., Hasager, C. B., Kirtzel, H.-J., and Hummelshøj, P.: Brief communication: Nowcasting of precipitation for leading-edge-erosion-safe mode, Wind Energ. Sci., 5(3), 977-981, doi: 10.5194/wes5-977-2020, 2020a.

Tilg, A.-M., Vejen, F., Hasager, C. B., and Nielsen, M.: Rainfall Kinetic Energy in Denmark: Relationship with Drop Size, Wind Speed, and Rain Rate, J. Hydrometeor., 21(7), 1621-1637, doi: 10.1175/JHM-D19-0251.1, 2020b. 
https://doi.org/10.5194/wes-2021-156

Preprint. Discussion started: 21 February 2022

(c) Author(s) 2022. CC BY 4.0 License.

1370 Tobin, N., Zhu, H. and Chamorro, L.P., 2015. Spectral behaviour of the turbulence-driven power fluctuations of wind turbines, Journal of Turbulence, 16(9), pp.832-846, 2015.

Turner, D. D., Wulfmeyer, V., Berg, L. K., and Schween, J. H.: Water vapor turbulence profiles in stationary continental convective mixed layers, J. Geophys. Res., doi: 10.1002/2014JD022202, 2014

Varlas, G., Katsafados, P., Papadopoulos, A., and Korres, G.: Implementation of a two-way coupled atmosphere-ocean wave modeling system for assessing air-sea interaction over the Mediterranean Sea, Atmospheric Research, 208, 201-217. doi: 10.1016/j.atmosres.2017.08.019, 2018.

Veers, P., Dykes K., Lantz, E., et al.: Grand challenges in the science of wind energy, Science, doi:10.1126/science.aau2027, 2019 .

Velarde, J., and Bachynski, E. E.: Design and fatigue analysis of monopile foundations to support the DTU 10 MW offshore 1380 wind turbine, Energy Procedia, 137, 3-13, doi: 10.1016/j.egypro.2017.10.330, 2017.

Viselli, A., Filippelli, M., Pettigrew, N., Dagher, H., and Faessler, N.: Validation of the first LiDAR wind resource assessment buoy system offshore the Northeast United States, Wind Energy, doi: 10.1002/we.2387, 2019.

Vorpahl, F., Schwarze, H., Fischer, T., Seidel, M., and Jonkman, J.: Offshore wind turbine environment, loads, simulation, and design, WIREs Energy Environ., 2, 548-570, doi:10.1002/wene.52, 2013.

1385 Wagner, R., Courtney, M., Gottschall, J., and Lindelöw-Marsden, P.: Accounting for speed shear in power performance measurement, Wind Energ., 14, 993-1004, https://doi.org/10.1002/we.509, 2011.

Wang, C., Campagnolo, F., Sharma, A., and Bottasso, C. L.: Effects of dynamic induction control on power and loads, by LES-ALM simulations and wind tunnel experiments, J. Phys.: Conf. Ser., 1618, 022036, doi: 10.1088/17426596/1618/2/022036, 2020.

1390 Wang, J., Balaprakash, P., and Kotamarthi, V.: Fast domain-aware neural network emulation of a planetary boundary layer parameterization in a numerical weather forecast model, Geoscientific Model Development Discussions, doi: 10.5194/gmd2019-79, 2019.

Wang, Q, Alappattu, D. P., Billingsley, S., et al.: CASPER: Coupled Air-Sea Processes and Electromagnetic Ducting Research, Bull. Amer. Meteor. Soc., 99 (7): 1449-1471. doi: 10.1175/BAMS-D-16-0046.1, 2018.

1395 Warner, J. C., Armstrong, B., He, R., and Zambon, J. B.: Development of a Coupled Ocean-Atmosphere-Wave-Sediment Transport (COAWST) Modeling System, Ocean Model., 35(3), 230-244, doi: 10.1016/j.ocemod.2010.07.010, 2010.

Wenegrat, J. O., and Arthur, R. S.: Response of the Atmospheric Boundary Layer to Submesoscale Sea Surface Temperature Fronts, Geophysical Research Letters, 45(24), 13,505-13,512, doi: 10.1029/2018GL081034, 2018.

Wise, A. S., and Bachynski, E. E.: Wake meandering effects on floating wind turbines, Wind Energy, 23, 1266-1285, doi: $1400 \quad 10.1002 /$ we. $2485,2020$.

Wood, R. L.: Stratocumulus Clouds, Mon. Wea. Rev., 140, 2373-2423,doi: 10.1175/MWR-D-11-00121.1, 2012. 
https://doi.org/10.5194/wes-2021-156

Preprint. Discussion started: 21 February 2022

(c) Author(s) 2022. CC BY 4.0 License.

Wood, R., and Bretherton, C. S.: Boundary layer depth, entrainment, and decoupling in the cloud-capped subtropical and tropical marine boundary layer, J., Clim., 17(18), pp. 3576-3588, doi: 10.1175/1520-

0442(2004)017<3576:BLDEAD>2.0.CO;2.

1405 Wilczak, J., Stoelinga, M., Berg, L. K., et al.: The Second Wind Forecast Improvement Project (WFIP2): Observational field campaign, Bull. Amer. Meteor. Soc., 100, 1701-1723, doi: 10.1175/BAMS-D-18-0035.1, 2019.

Wu, K. L., and Porté-Agel, F.: Flow adjustment inside and around large finite-size wind farms, Energies, 10, 2017.

Wu, L., Breivik, Ø., and Rutgersson, A.: Ocean-Wave-Atmosphere Interaction Processes in a Fully Coupled Modeling Systemc, Journal of Advances in Modeling Earth Systems, 11(11), 3852-3874, doi: 10.1029/2019MS001761, 2019.

1410 Wu, W.-C., Wang, T., Yang, Z., and García-Medina, G.: Development and validation of a high-resolution regional wave hindcast model for US West Coast wave resource characterization, Renewable Energy, 152: 736-753, 2020.

Wu, Y-T., and Porté-Agel, F.: Atmospheric Turbulence Effects on Wind-Turbine Wakes: An LES Study, Energies, 5, 53405362; doi:10.3390/en5125340, 2012.

WW3DG: The WAVEWATCH III Development Group: User manual and system documentation of WAVEWATCH III 1415 version 6.07, 333, College Park, MD, USA: NOAA/NWS/NCEP/MMAB, https://www.researchgate.net/publication/336069899_User_manual_and_system_documentation_of_WAVEWATCH_III_R version 607, 2019.

Yang, D., Meneveau, C., and Shen, L.: Dynamic modelling of sea-surface roughness for large-eddy simulation of wind over ocean wavefield, Journal of Fluid Mechanics, 726, 62-99, 2013.

1420 Yang, D., Meneveau, C., and Shen, L.: Effect of downwind swells on offshore wind energy harvesting - A large-eddy simulation study, Renew. Energy, 70, 11-23, doi:10.1016/j.renene.2014.03.069, 2014.

Yang, Z., Deng, B.-Q., and Shen, L.: Direct numerical simulation of wind turbulence over breaking waves, Journal of Fluid Mechanics, 850, 120-155, doi:10.1017/jfm.2018.466, 2018.

Zeng, X., Brunke, M. A., Zhou, M., Fairall, C., Bond, N. A., and Lenschow, D. H.: Marine atmospheric boundary layer

1425 height over the eastern Pacific: data analysis and model evaluation, J. Clim., 17(21), pp. 4159-4170, doi: 10.1175/JCLI3190.1.

Zhang, J., Huang, L., Wen, Y. and Deng, J.: A distributed coupled atmosphere-wave-ocean model for typhoon wave numerical simulation, Int. J. Comput. Math., 86(12), 2095-2103, doi:10.1080/00207160802047632, 2009.

Zhang, S., Liu, Z., Zhang, X., Wu, X., Han, G., Zhao, Y., Yu, X., Liu, C., Liu, Y., Wu, S., Lu, F., Li, M. and Deng, X.:

1430 Coupled data assimilation and parameter estimation in coupled ocean-atmosphere models: a review, Clim. Dyn., 54, 51275144, doi:10.1007/s00382-020-05275-6, 2020. 